\title{
Nercc1, a mammalian NIMA-family kinase, binds the Ran GTPase and regulates mitotic progression
}

\author{
Joan Roig, Alexei Mikhailov, Christopher Belham, and Joseph Avruch ${ }^{1}$ \\ Department of Molecular Biology and the Diabetes Unit and Medical Services, Massachusetts General Hospital, \\ and the Department of Medicine, Harvard Medical School, Boston, Massachusetts 02114, USA
}

\begin{abstract}
The protein kinase NIMA is an indispensable pleiotropic regulator of mitotic progression in Aspergillus. Although several mammalian NIMA-like kinases (Neks) are known, none appears to have the broad importance for mitotic regulation attributed to NIMA. Nercc1 is a new NIMA-like kinase that regulates chromosome alignment and segregation in mitosis. Its NIMA-like catalytic domain is followed by a noncatalytic tail containing seven repeats homologous to those of the Ran GEF, RCC1, a Ser/Thr/Pro-rich segment, and a coiled-coil domain. Nerce1 binds to another NIMA-like kinase, Nek6, and also binds specifically to the Ran GTPase through both its catalytic and its RCC1-like domains, preferring RanGDP in vivo. Nercc1 exists as a homooligomer and can autoactivate in vitro by autophosphorylation. Nercc1 is a cytoplasmic protein that is activated during mitosis and is avidly phosphorylated by active p34 ${ }^{\text {Cde2 }}$. Microinjection of anti-Nercc1 antibodies in prophase results in spindle abnormalities and/or chromosomal misalignment. In Ptk2 cells the outcome is prometaphase arrest or aberrant chromosome segregation and aneuploidy, whereas in CFPAC-1 cells prolonged arrest in prometaphase is the usual response. Nercc1 and its partner Nek6 represent a new signaling pathway that regulates mitotic progression.
\end{abstract}

[Key Words: NIMA; NEK; Ran; RCC1; cdc2/MPF; mitosis]

Received December 20, 2001; revised version accepted May 16, 2002.

Cell division is timed and controlled in part through the interplay of a specialized set of protein kinases and phosphatases, the best known of which are the cyclin-dependent kinases (CDK). Recent studies indicate, however, that several other families of protein kinases also play important roles at different stages of this intricate process (Nigg 2001). Polo-like kinases (Glover et al. 1998), Aurora kinases (Bischoff and Plowman 1999), and NIMA-like kinases (Neks) (Fry and Nigg 1997; Kandli et al. 2000) have been implicated in such processes as centrosome separation and chromosome condensation in prophase, nuclear envelope breakdown and spindle assembly in prometaphase, as well as in exit from mitosis and cytokinesis.

Neks are named for the Aspergillus nidulans protein kinase encoded by the nimA gene (Osmani and Ye 1996). Early data suggested that NIMA cooperates with p34 ${ }^{\mathrm{Cdc} 2} /$ cyclin B during the onset of mitosis, perhaps by enabling nuclear entry of cyclin $\mathrm{B} / \mathrm{p} 34^{\mathrm{Cdc} 2}$ (Wu et al. 1998). Moreover, both Cdc2 and NIMA must be inactivated for mitotic exit. Temperature-sensitive mutations

${ }^{1}$ Corresponding author.

E-MAIL avruch@helix.mgh.harvard.edu; FAX (617) 726-5649.

Article and publication are at http://www.genesdev.org/cgi/doi/10.1101/ gad. 972202 . of the nimA gene (Osmani et al. 1991a) or expression of the noncatalytic domain of NIMA (Lu and Means 1994) arrest Aspergillus cells in $\mathrm{G}_{2}$ (thus the name NIM, never in mitosis) without interfering with $\mathrm{p} 34^{\mathrm{Cdc} 2}$ activation. Conversely, overexpression of NIMA causes chromatin condensation and abnormal spindle formation without activating p34 ${ }^{\mathrm{Cdc} 2}$ (Osmani et al. 1988a; O'Connell et al. 1994). $G_{2}$ arrest of $\operatorname{nim} A$ mutants can be bypassed by mutation of different anaphase-promoting complex (APC) subunits. Double nim $A+A P C$ mutants can enter mitosis when shifted to restrictive temperature, although mitotic cells show aberrant nuclear envelopes and spindle organization, pointing to an involvement of the NIMA protein kinase in mitotic processes beyond the control of the $\mathrm{G}_{2} / \mathrm{M}$ transition (Osmani et al. 1988b, 1991b; Lies et al. 1998).

NIMA protein levels are maximal during mitosis, and NIMA protein kinase activity seems to parallel NIMA protein content (Osmani et al. 1991b; Ye et al. 1995). NIMA is hyperphosphorylated in vivo during mitosis and can be phosphorylated in vitro by $334^{\mathrm{Cdc} 2}$ (Ye et al. 1995). Such in vitro phosphorylation alters NIMA protein kinase activity modestly; however, once phosphorylated in mitosis, NIMA is rapidly degraded, and this degradation is necessary for mitotic exit $\left(\mathrm{O}^{\prime}\right.$ Connell et al. 1992; Pu and Osmani 1995). 
The ability of recombinant NIMA to induce chromatin condensation in fission yeast (O'Connell et al. 1994) and vertebrate cells (accompanied in the latter by nuclear membrane breakdown; O'Connell et al. 1994; Lu and Hunter 1995) as in Aspergillus, suggests that a protein kinase with similar specificity participates in cell cycle control in higher metazoans. At least eight mammalian NIMA-related kinases, or Neks (Nigg 2001), have been identified; however, none has emerged as a bona fide functional homolog of NIMA, that is, as necessary for mitotic progression, or able to induce chromatin condensation if overexpressed. The Neks are most closely related to NIMA in their catalytic domain sequences, but each diverges substantially from NIMA in its noncatalytic C-terminal tail, including the Neurospora crassa NIMA-related kinase that has the capacity to complement the nimA mutation (Pu et al. 1995). Nek2, the mammalian homolog most similar in overall amino acid sequence to NIMA, is involved in the regulation of centrosomal structure and function (Mayor et al. 1999), but does not appear to be involved in other aspects of mitosis. The functions of other Neks are largely unknown, although recently Nek6, and the closely related Nek7, recent mammalian additions to the family (Kandli et al. 2000), were shown to phosphorylate the protein kinase p70 S6 kinase on Thr412 within a hydrophobic motif, a phosphorylation that, together with the PDK1catalyzed phosphorylation of Thr252 in the activation loop, mediates activation of the p70 S6 kinase (Belham et al. 2001).

Herein we describe a new member of the NIMA-like family of protein kinases, which we designate Nercc1 kinase. This enzyme was identified by its tight binding to overexpressed recombinant Nek6. Nerccl kinase is activated during mitosis, binds specifically to the Ran GTPase, and is a substrate for Cdc2 phosphorylation. Overexpression of both active and inactive variants of the Nercc1 kinase is toxic to cells, inhibiting cell division and causing abnormal nuclear morphologies. Microinjection of anti-Nerccl antibodies in prophase, that is, after chromosome condensation, interferes with spindle organization and correct segregation of the chromosomes, resulting in either prometaphase arrest or aneuploidy. Nerccl kinase appears to play one or more central roles in the control of mitotic progression, possibly regulated by $\mathrm{p} 34^{\mathrm{Cdc} 2}$ and the Ran GTPase.

\section{Results}

Cloning of Nercc1, a novel protein kinase in the NIMA family

Immunoaffinity purification of a Flag-Nek6 polypeptide overexpressed in HEK293 cells results in the recovery of an associated $120-\mathrm{kD}$ polypeptide. Incubation of the Flag-Nek6 immunoprecipitate with $\mathrm{Mg}^{2+}$ plus $\left[\gamma^{-32} \mathrm{P}\right]$ ATP yields ${ }^{32} \mathrm{P}$ incorporation into both Nek6 and p120 to a similar extent, suggesting that p120 is a substrate for Nek6, a protein kinase itself, or both (Fig. 1a).
Tryptic digests of the $120-\mathrm{kD}$ band were analyzed by electrospray ionization mass spectrometry. Spectra corresponding to multiple peptide sequences were identified on each of three successive ORFs predicted by GENESCAN (Burge and Karlin 1997) on the human BAC clone 201F1 (AC007055). The sum of the molecular masses of the three polypeptides predicted by these ORFs was close to $120 \mathrm{kD}$, suggesting that the exonintron boundaries had been determined incorrectly by GENESCAN. Further analysis, using GENEMARK (Borodovsky and McIninch 1993) or GENESCAN, yielded predictions containing all three original ORFs (AAD31938, AAD31939, and AAD31940) in polypeptides of $\sim 100 \mathrm{kD}$ (107 kD and $91 \mathrm{kD}$, respectively).

Using the predicted sequences and supporting ESTs, a cDNA containing the complete coding region for a protein of 979 residues containing all the peptides identified by MS was cloned by PCR (see Supplementary Fig. 1a; the nucleotide sequence along with a translation of the coding region is shown in Supplementary Fig. 1b; Supplemental Material available online at http://www. genesdev.org). The predicted protein product (Fig. 1b) has a calculated molecular mass of $107,034 \mathrm{D}$, a theoretical pI of 5.50, and contains all 29 peptides detected in the tryptic digest of the $120-\mathrm{kD}$ protein band. The polypeptide has a typical eukaryotic protein kinase domain situated near the $\mathrm{N}$ terminus (residues 52-308) that shows all the features of a functional serine/threonine protein kinase. The catalytic domain is most similar to the NIMA-related family of protein kinases $(39 \%-44 \%$ identity and 56\%-66\% similarity with vertebrate Neks, 33\% identity and $49 \%$ similarity with NIMA). Immediately following the catalytic domain is a nuclear localization signal (NLS) composed of two classical nuclear localization motifs $\int_{306}$ PLLRKRRR $_{313}$ and ${ }_{325} \mathrm{PTKRPR}_{330}$ ). Thereafter is a domain containing seven consecutive RCC1 (regulator of chromosome condensation) repeats (residues 347-726; Fig. 1c), followed by a segment containing nine consecutive glycine residues (752-760), encompassed within a PEST region (734-779); the polyglycine segment is likely to act as a flexible hinge. An acidic serine/threonine/proline-rich segment (761-890) follows next, which includes two motifs that conform to the SH3-domain-binding sequence PXXP $\left.\right|_{823}$ PXPXXPXP $_{830}$ and ${ }_{881} \mathrm{KXXPXXPP}_{888}$ ), and seven SP and TP sites (four overlapping the PXXP motifs). Immediately succeeding this region is a predicted coiled-coil domain (891-940), followed by the protein $\mathrm{C}$ terminus. We designate this polypeptide as Nercc1 kinase, based on the similarity of the kinase domain to the NIMA/Nek kinases, and the presence of an RCC1-like domain.

Although there is no significant identity in the primary sequences of the C-terminal noncatalytic segments of NIMA and the Nerccl kinase, these two segments do share several related features, namely, a nuclear localization signal immediately following the catalytic domain, a proline-rich segment containing multiple SP and TP sites (some of which, in the case of NIMA, are probably phosphorylated during mitosis and appear to be important for regulation; Fry and Nigg 1995; Osmani and 
Roig et al.

\section{a}

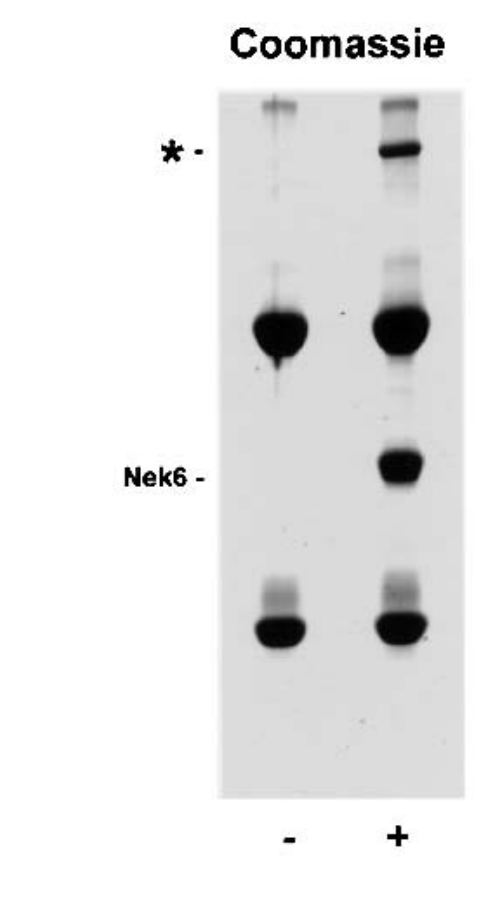

${ }^{32} \mathbf{P}$ autorad.

b

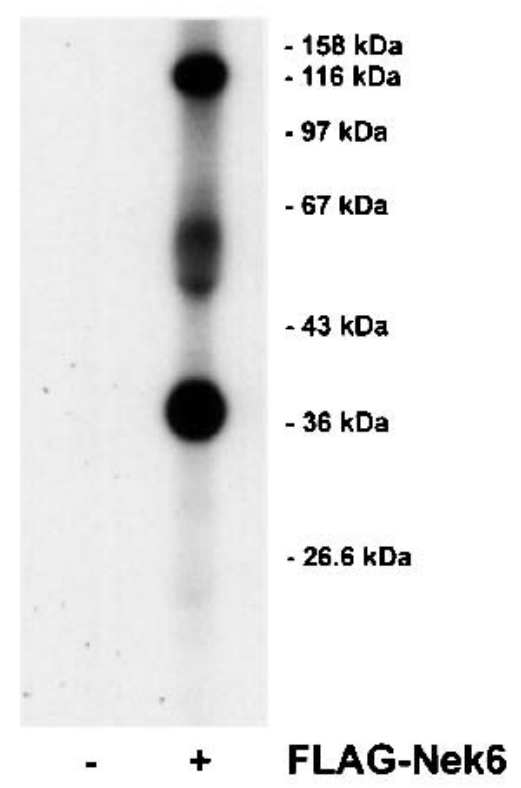

b
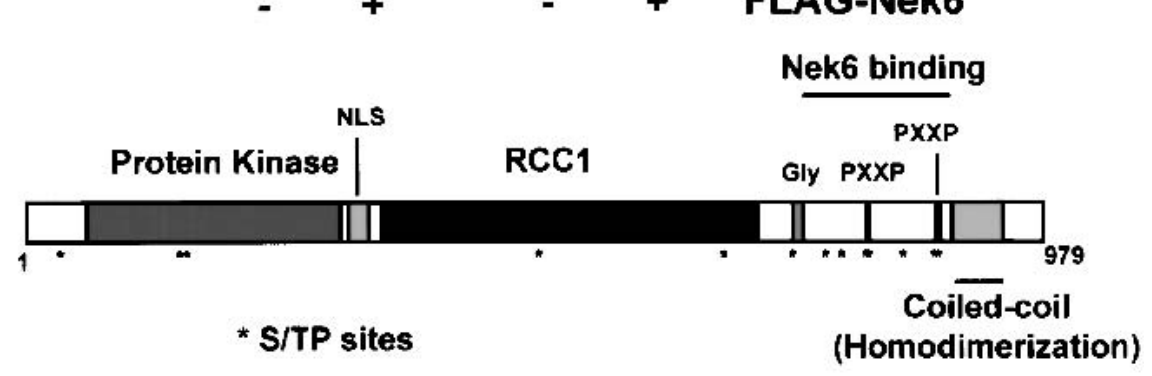

C

Figure 1. Nek 6 coimmunoprecipitates with a 120-kD protein. Structure of Nercc1 polypeptide. (a) HEK293 cells were transfected with either empty vector (-) or pCM5 Flag-Nek6 (+). Cell lysates were prepared $48 \mathrm{~h}$ later, and Nek6 was immunoprecipitated using an anti-Flag antibody. The washed immunoprecipitates were incubated with $\mathrm{Mg}^{2+}\left[\gamma_{-}{ }^{32} \mathrm{P}\right] \mathrm{ATP}$. Coomassie stain (left panel) and ${ }^{32} \mathrm{P}$ autoradiography (right panel) of the gel are shown. (b) Cartoon of Nercc1 polypeptide domain structure. (NLS) Nuclear localization signal; (RCC1) RCC1 homology domain; (Gly) polyglycine stretch; (PXXP) proline-rich motifs; (S/TP sites) Ser/ThrPro motifs. (c) Alignment of the RCC1 repeats of the human regulator of chromosome condensation (RCC1) with Nercc1 RCC1 domain repeats. Amino acid numbers are shown. Of the 10 residues known to be important for the exchange activity of RCC1 toward Ran (i.e., affecting the $K_{\mathrm{m}}$ or $K_{\text {cat }}$ Ji et al. 1999), Nercc1 lacks a conserved residue corresponding to RCC1 D44, R206, D182, and H270, although a residue of similar charge exists at the position -1 and +1 for the latter two; D128 E157 and H304 are conserved, whereas H78, R101 and H410 are substituted by similarly charged residues. Notably, mutation of RCC1 D182 (an asparagine in Nercc1) results in a protein with no measurable GEF activity.

Ye 1996), and a coiled-coil domain. In addition, several PEST regions (involved in control of protein stability) are found in both protein kinases.

A striking difference between Nerccl protein kinase, NIMA, and the Neks characterized thus far in higher eukaryotes is the presence in the Nerccl kinase of a domain homologous to the RCC1 protein. RCC1 is a guanine-nucleotide-exchange factor for the small G-protein Ran, and is composed of seven repeats of 51-68 residues folded in a structure that resembles a seven-blade pro- 
peller (Renault et al. 1998). The Nercc1 RCC1 domain has a $27 \%$ identity and $43 \%$ similarity to RCC1, and like RCC1 contains seven tandem repeats (Fig. 1c). We have been unable to detect a protein kinase with this domain organization in lower eukaryotes; interestingly, a hypothetical protein kinase in the genome of Drosophila melanogaster (accession code AAF56344) shows an architecture homologous to Nerccl kinase, that is, an N-terminal NIMA-related protein kinase domain followed by a series of RCC1 domain repeats.

During the revision of this paper, the sequences of two different mammalian NIMA-family kinases containing an RCC1 domain appeared in GenBank. One, cloned from mouse (accession code AF407579) and zebrafish (AF407580) by Beier and colleagues (S. Liu, W. Lu, T. Obara-Ishibara, I. Drummond, and D.R. Beier. A defect in a novel Nek-family kinase causes cystic disease in the mouse and in zebrafish. unpubl.), has been named Nek8. Mouse Nek 8 is a protein of 698 residues, $32 \%$ identical and $49 \%$ similar to the first 752 residues of Nercc1. It lacks the C-terminal tail that in Nerccl spans from the polyglycine region to the end of the protein; this is an important regulatory region in Nerccl (see below). A second protein kinase identical in sequence to Nerccl has been deposited in GenBank; this can be accessed both as Nek8 (AY048580) and Nek9 (NM033116) (Holland et al. 2002).

The Nerccl protein kinase is expressed in all human cell lines tested, including HEK293, HeLa, and U2OS cells; Nercc1 protein expression is detected in these and other mammalian cell lines, as well as in all mouse tissues tested (see Supplemental Fig. 2).

\section{Nercc1 interaction with Nek6}

We sought to confirm the association of Nek6 with recombinant Nercc1 by coexpression of GST-Nek6 and Flag-Nercc1 in 293 cells. Full-length Flag-Nercc1 is seen to bind specifically to GST-Nek6, whereas the Cterminally truncated Flag-Nercc1(1-739), despite comparable expression, is unable to bind GST-Nek6 (Fig. 2a). Reciprocally, the fusion of the Nerccl kinase C-terminal segment, Nercc1(732-979), to GST is sufficient to enable specific binding of Flag-Nek6 (Fig. 2b). Further analysis (see below) indicates that the site of Nek6/ Nerccl interaction lies between the Nerccl amino acids 732 and 891.

Nercc1 homodimerizes through a coiled-coil domain distinct from the Nek6-binding site

Nerccl contains a predicted coiled-coil motif near its C terminus (residues 891-940), a likely candidate for an oligomerization domain (Fig. 3a). The ability of Nercc1 to form homooligomers is shown by the coprecipitation of Flag-Nercc1 with HA-Nerccl (Fig. 3b). The Nercc1(891-940) segment was fused to GST and coex- a

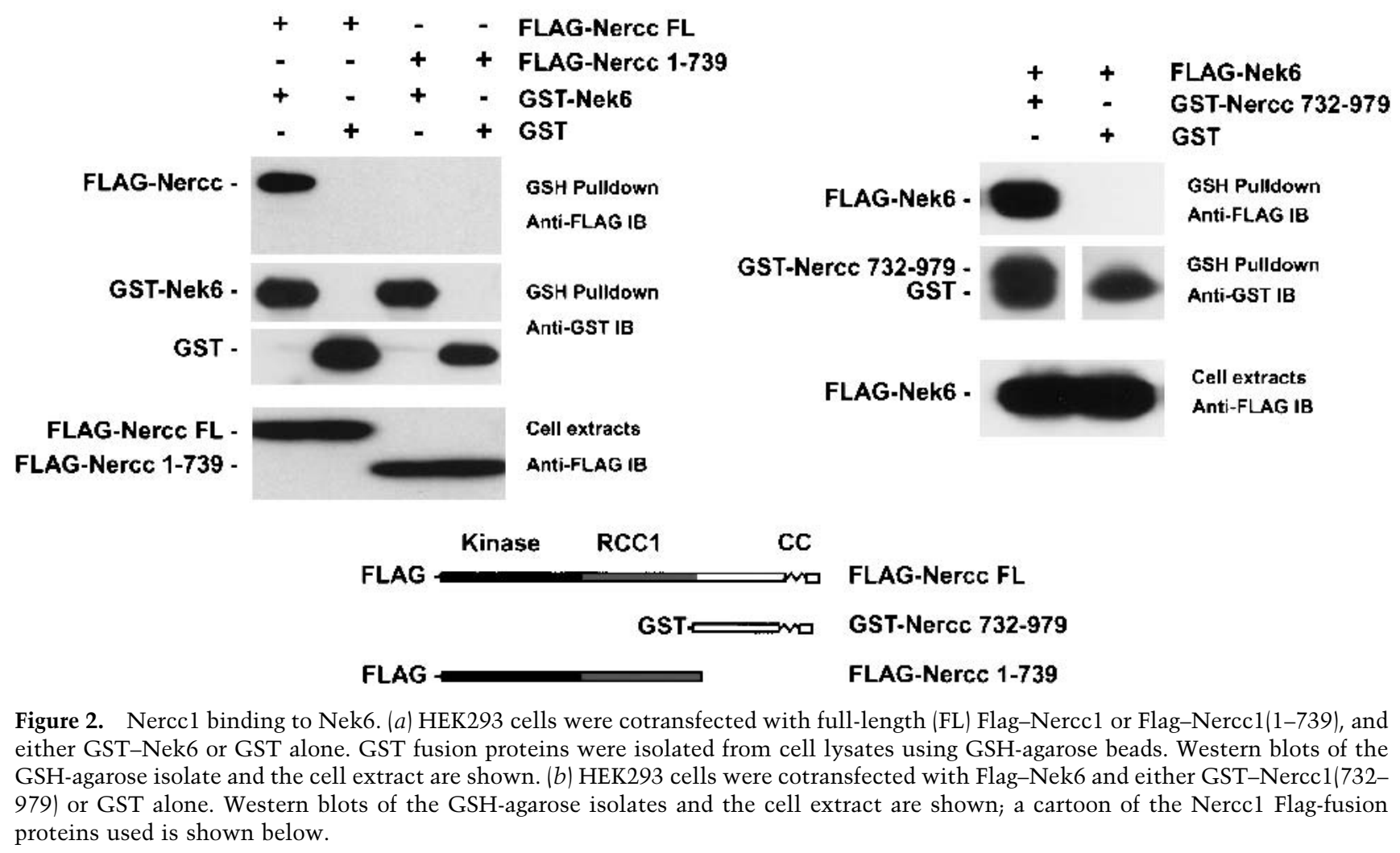

b 


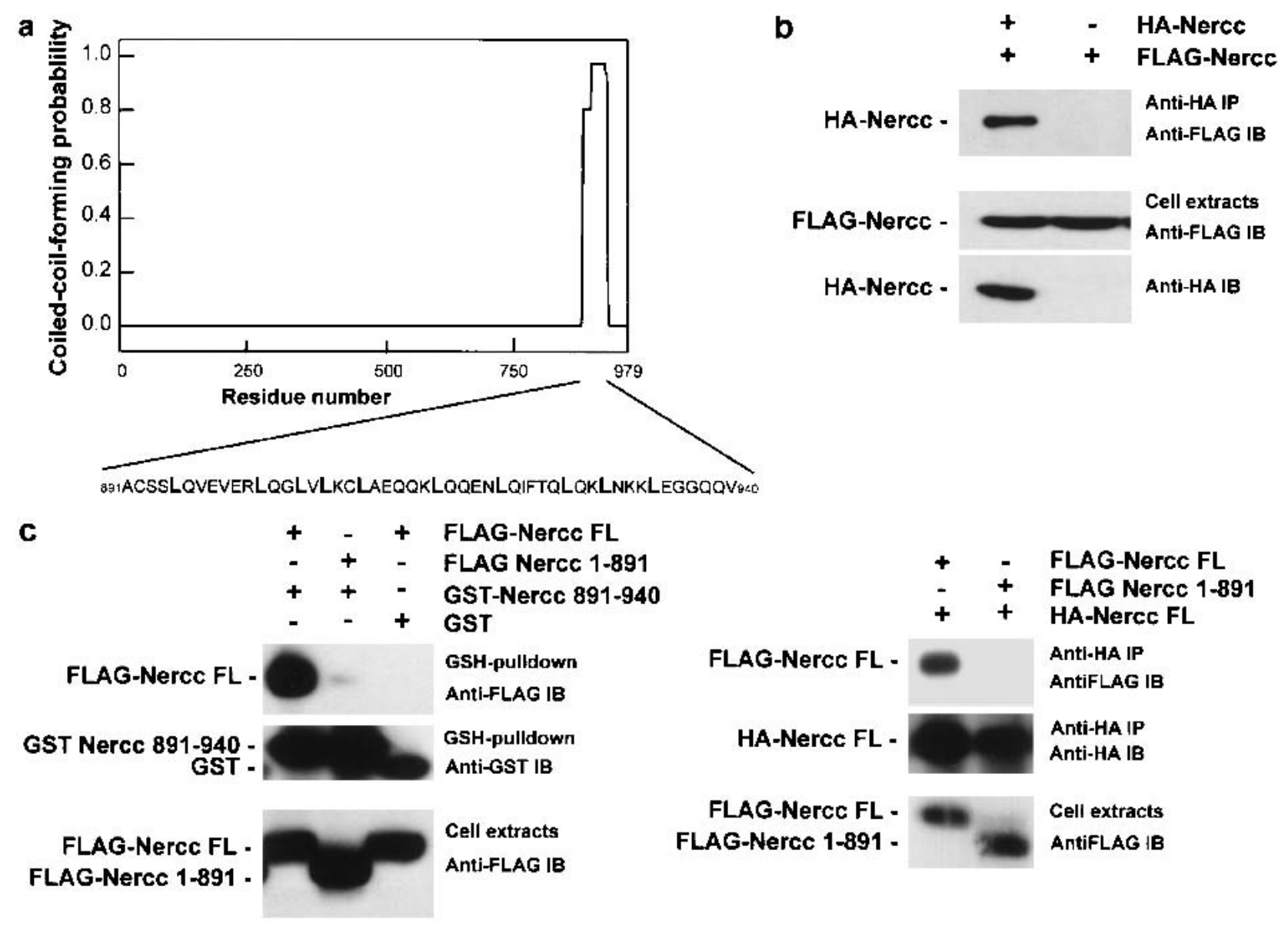

d

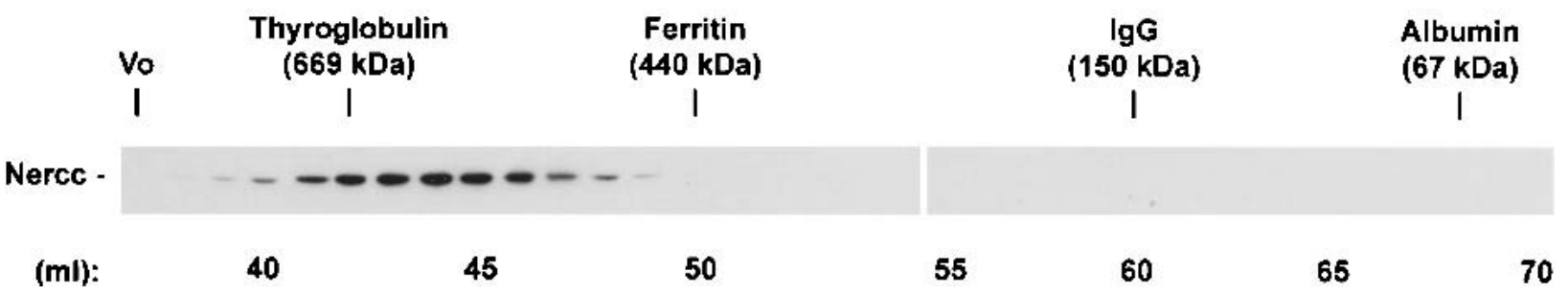

Figure 3. Nerccl oligomerizes through its C-terminal coiled-coil domain. (a) Nerccl coiled-coil prediction carried out with the Coils 2.1. software (window 28). The propensity of a sequence to form coiled coils on a scale from 0 to 1 is plotted against the linear sequence of amino acids. The sequence of the predicted coiled coil is shown; leucine residues are shown in bold. $(b)$ HEK293 cells were transfected with HA-Nercc1 and Flag-Nercc1. The anti-HA immunoprecipitate was blotted with anti-Flag antibody (upper panels); expression of the constructs is shown below. (c, left panels) HEK293 cells were transfected with Flag-Nercc1 full-length (FL) or Flag-Nercc1(1-891) and either GST or a GST fusion to the Nercc1 coiled-coil GST-Nercc1(891-940). GST-agarose isolates were blotted for Flag (upper panel) or GST (middle panel); Flag-Nerccl expression in cell lysates is shown in the lower panel. (Right panels) Flag-Nercc1 (FL) or Flag-Nercc1(1-891) were cotransfected with HA-Nercc1 (FL). The HA immunoprecipitates were blotted for Flag (upper panel) or HA (middle panel); expression of Flag-Nercc1 in cell lysates is shown in the lower panel. (d) Gel filtration of Nercc1 endogenous to HEK293 cells. The median elution position of standard proteins (thyroglobulin, ferritin, IgG, and BSA) is indicated.

pressed with either full-length Flag-Nercc1 or FlagNercc1 deleted of its C-terminal 89 residues (Nercc1 residues 1-891). Figure 3c shows that although fulllength Nerccl associates specifically with GSTNercc1(891-940), deletion of the C-terminal 89 residues of Nerccl abolishes this association (Fig. 3c, left panel). In addition, Nercc1(1-891) cannot oligomerize with fulllength Nercc1 (Fig. 3c, right panel). Thus, Nercc1 oligo- merizes through its C-terminal coiled-coil domain. As shown below, this oligomerization is important for the regulation of Nerccl protein kinase activity.

Gel filtration analysis of both recombinant and endogenous Nercc1 in 293 cells shows that the protein kinase exists in a high molecular mass complex of $\sim 600 \mathrm{kD}$ (Fig. $3 d$ ). The larger-than-expected size probably reflects the association of Nercc1 with other proteins such as Nek6, 
and perhaps higher-order homooligomers and/or a complex of asymmetric shape.

The 891-940 deletion does not affect Nek6 interaction with Nercc1; full-length Nercc1 and Nercc1(1-891) both interact with Nek6 with similar affinities. Moreover, GST-Nercc1(891-940) does not bind Nek6 (data not shown). Thus, Nek6 binds to Nercc1 between amino acids 732 and 891, that is, in the region between the end of the Nercc1 RCC1 domain and the beginning of the coiled-coil domain.

\section{Protein kinase activity of Nercc1}

The catalytic properties of Nerccl were studied using immunoprecipitates of Flag-tagged forms of the Nercc1 polypeptide transiently expressed in HEK293 cells. The specificity of the measured protein kinase activity for the Nerccl polypeptide was verified by the inability of an ATP-binding site mutant of Nercc1 (K81M) to catalyze significant ${ }^{32} \mathrm{P}$ transfer to itself or exogenous substrates (Fig. 4b, lanes 3,4). Thus, the kinase activity described below is caused by Nerccl and not a contaminating protein kinase (e.g., Nek6). Nercc1 can autophosphorylate and phosphorylate different histones and MBP, whereas $\beta$-casein is phosphorylated much less rapidly (data not shown). Phosphoamino acid analysis of Nercc 1 autophosphorylation and phosphorylation of histone $\mathrm{H} 3$ showed that Nercc1 phosphorylates serine and threonine residues exclusively (data not shown). Recombinant wild-type Nercc1 has low basal activity when extracted from exponentially growing cells; however, preincubation with $\mathrm{Mg}^{2+}$ plus ATP $(100 \mu \mathrm{M})$ induces Nercc1 autophosphorylation (accompanied by a slowing in electrophoretic mobility) and activation (this activation can be reversed by phosphatase treatment; see below). The rate of in vitro activation is greatly enhanced if $\mathrm{Mn}^{2+}$ replaces $\mathrm{Mg}^{2+}$ (data not shown). Autophosphorylation/autoactivation is time and ATP concentration dependent; importantly, $10 \mu \mathrm{M}$ ATP fails to enable significant Nerccl activation even after incubation times of 90 min at $25^{\circ} \mathrm{C}$, whereas $100 \mu \mathrm{M}$ ATP gives maximal activation (10- to 20 -fold) by $60 \mathrm{~min}$, with half-maximal activation at $20 \mathrm{~min}$ (Fig. 4a). Once activation is complete, Nercc1 catalyzes a robust phosphorylation of $\mathrm{H} 3$ at $5 \mu \mathrm{M}$ to $10 \mu \mathrm{M}$ ATP. This apparent increase in affinity for ATP after activation enables the design of a Nerccl kinase assay that reflects the extent of activation achieved. Notably, endogenous Nercc1, immunoprecipitated out of exponentially growing cells by specific antibodies, shows a similar pattern of $\mathrm{Mg}^{2+}$ ATP-dependent autoactivation in vitro. Nerccl is able to use GTP as a phosphate donor; GTP supports autoactivation, and after maximal autoactivation in vitro, enables the phosphorylation of histone $\mathrm{H} 3$ at $\sim 30 \%$ the rate observed with ATP (data not shown).

We next carried out a structure-function analysis of the ability of recombinant Nerccl kinase to autoactivate in vitro. A series of Nerccl variants, transiently expressed in HEK293 cells, was assayed for H3 kinase activity after preincubation at $25^{\circ} \mathrm{C}$ for 30 min with $\mathrm{Mg}^{2+}$ alone or $\mathrm{Mg}^{2+}$ plus $100 \mu \mathrm{M}$ ATP, the latter a condition sufficient to enable near-maximal autoactivation of wild-type Nercc1 (Fig. 4a). After washing away the nonradioactive $\mathrm{ATP}$, the $\mathrm{H} 3$ kinase assay was commenced using a concentration of $\left[\gamma^{-32} \mathrm{P}\right] \mathrm{ATP}(5 \mu \mathrm{M}$ to $10 \mu \mathrm{M})$ below that capable of supporting autoactivation of wildtype Nercc1 kinase (Fig. 4b, lanes 1,2). An ATP-binding loop mutant of Nercc1 (K81M) shows no significant autophosphorylation/kinase activity irrespective of preincubation with $\mathrm{Mg}^{2+}$ ATP (Fig. 4b, lanes 3,4); this is also true of Nercc1(338-979), which lacks entirely the Nercc1 protein kinase domain (data not shown). Nercc1(1-391), which lacks the RCC1 domain and the C-terminal tail, shows a low basal protein kinase activity but can be modestly activated by preincubation with $\mathrm{Mg}^{2+}$ and $100 \mu \mathrm{M}$ ATP (Fig. 4b, lanes 5,6, and 4c); Nercc1 $(1-391, \mathrm{~K} 81 \mathrm{M})$ is entirely devoid of activity (Fig. $4 \mathrm{~b}$, lanes 7,8$)$, as is $\operatorname{Nercc1}(1-308)$, which terminates the end of the canonical kinase domain (data not shown). Nercc1(1-739) retains both the protein kinase domain and the RCC1 domain, but is nevertheless inactive and incapable of autoactivation (Fig. 4b, lanes 9,10). Deletion of the coiled-coil domain Nercc1(1-889) greatly diminishes the rate of autoactivation (Fig. 4b, lanes 11,12), whereas deleting the proline-rich C-terminal segment but retaining the coiled coil $(\Delta 763-889)$ permits substantial autoactivation (Fig. 4b, lanes 13,14). Selective deletion of the RCC1 domain, Nercc1( $\Delta 347-732)$, results in a very high basal H3 kinase activity as compared with wild-type Nercc1, which is not further increased by preincubation in vitro with $\mathrm{Mg}^{2+}$ plus $100 \mu \mathrm{M}$ ATP (Fig. 4b, lanes 15,16, and 4c). A more detailed examination of the time course of activation by ATP $(100 \mu \mathrm{M})$ shows that although both Nercc1(1-391) and Nercc1(1-889) are capable of autoactivation, the rate is greatly diminished as compared with wild type. Thus deletion of the RCC1 domain produces a mutant with a basal activity similar to the maximal attainable by autoactivation (although the $\Delta 347-732$ polypeptide is less stable at $25^{\circ} \mathrm{C}$ ); however, if the C-terminal dimerization domain is also deleted, as in Nercc1(1-391), the basal activity returns to low levels and autoactivation is severely retarded.

These results suggest a mechanism for Nerccl kinase regulation (at least in vitro) in which the Nerccl homodimer is maintained in an inhibited state by the ability of the RCC1 domain to abrogate intramolecular autophosphorylation. The inability of autoactivation to occur at ATP concentrations that enable robust phosphate transfer once activation has occurred suggests that the inhibitory action of the RCC1 domain operates, at least in part, by obstruction of the ATP-binding site. One prediction of this model is that the RCC1 domain and the kinase domain of Nercc1 are likely to interact. The occurrence of such an interaction is shown in Figure $4 \mathrm{~d}_{\text {; }}$ Flag-Nercc1(338-739) expressed in HEK293 cells associates directly with coexpressed HA-Nercc1(1-391), supporting the view that the RCC1 domain may inhibit the kinase domain through a direct interaction. Nerccl autophosphorylation is likely to occur in trans within the homodimer, as deletion of the RCC domain results in 
Roig et al.

a
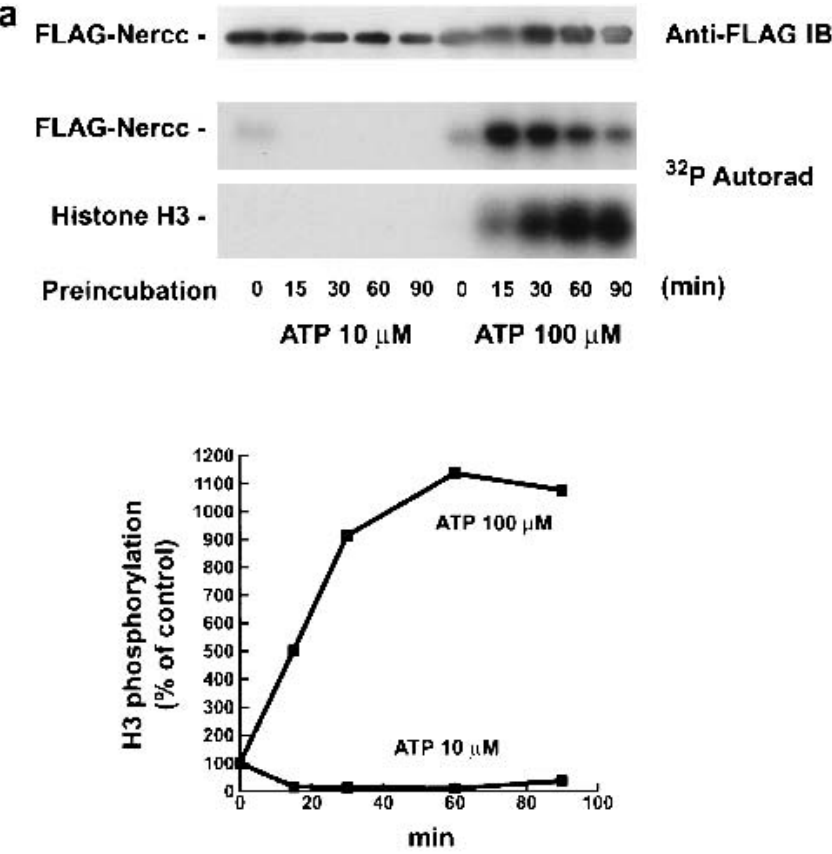

b

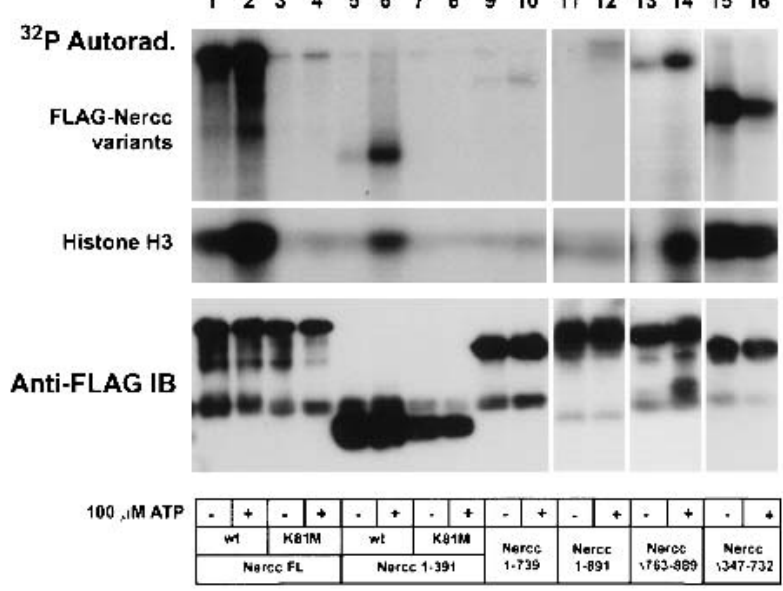

C

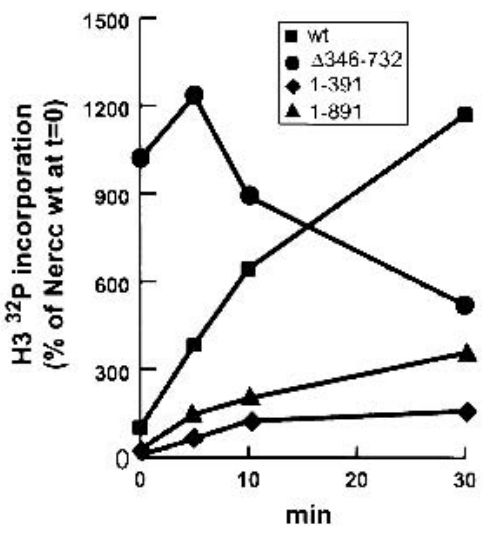

d

HA-Nercc 1-391 + +

FLAG-Nercc 338-779 + -

HA-Nercc 1-391. Anti-FLAG IP

Anti-HA IB

FLAG-Nercc 338-739 -

Anti-FLAG IP

Anti-FLAG IB

HA-Nercc 1-391 - $\bigcirc$ Cell extracts
Anti-HA IB

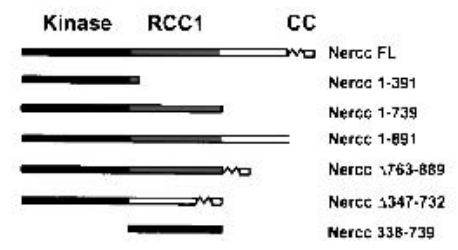

Figure 4. Nerccl autoactivation in vitro. (a) Flag-Nerccl was immunoprecipitated from HEK 293 cells, washed, and incubated at $25^{\circ} \mathrm{C}$ in phosphorylation buffer for the indicated times with $10 \mu \mathrm{M}$ or $100 \mu \mathrm{M}$ ATP. Incubations were terminated by washing, followed by the addition of $10 \mu \mathrm{M}\left[{ }^{32} \mathrm{P}\right] \mathrm{ATP}$ and histone $\mathrm{H} 3(1 \mu \mathrm{g} / 50 \mu \mathrm{L})$. After $10 \mathrm{~min}$ at $30^{\circ} \mathrm{C},{ }^{32} \mathrm{P}$ incorporation was stopped by addition of SDS sample buffer, followed by SDS-PAGE and blot transfer. The anti-Flag immunoblot (upper panel), ${ }^{32} \mathrm{P}$ autoradiography (middle panel), and the relative quantity of ${ }^{32} \mathrm{P}$ incorporated into histone $\mathrm{H} 3$ (bottom panel) are shown. (b) Immobilized Flag-tagged Nercc1 variants, isolated after transient expression in HEK293 cells, were washed and incubated in phosphorylation buffer at $25^{\circ} \mathrm{C}$ for 30 min with $\mathrm{Mg}^{2+}$ and with or without $100 \mu \mathrm{M}$ ATP. After an additional wash, samples were incubated at $30^{\circ} \mathrm{C}$ with $\mathrm{Mg}^{2+}$ plus $10 \mu \mathrm{M}\left[{ }^{32} \mathrm{P}\right] \mathrm{ATP}$ and histone $\mathrm{H} 3(1 \mu \mathrm{g} / 50 \mu \mathrm{L})$. After $10 \mathrm{~min}$ the reaction was stopped by addition of SDS sample buffer followed by SDS-PAGE and blot transfer. The ${ }^{32} \mathrm{P}$ autoradiogram (upper panel) and anti-Flag immunoblot (middle panel) are shown. (c) Time course of activation of the

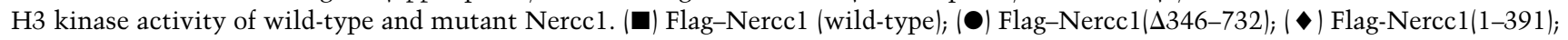
and (A) Flag-Nercc1(1-891), were expressed in HEK293 cells, immobilized on anti-Flag-agarose, washed and incubated at $25^{\circ} \mathrm{C}$ with $\mathrm{Mg}^{2+}$ plus $100 \mu \mathrm{M}$ ATP. At the times indicated, samples were washed, followed by addition of $\mathrm{Mg}^{2+}$ plus $10 \mu \mathrm{M}\left[{ }^{32} \mathrm{P}\right] \mathrm{ATP}$ and histone $\mathrm{H} 3(1 \mu \mathrm{g} / 50 \mu \mathrm{L})$. After $10 \mathrm{~min}$ at $30^{\circ} \mathrm{C}$, SDS sample buffer was added, and ${ }^{32} \mathrm{P}$ incorporation into $\mathrm{H} 3$ was measured (using a PhosphorImager) after SDS-PAGE and blot transfer. ${ }^{32} \mathrm{P}$ incorporation is expressed as a percentage of Nerccl wild-type value at $t=0$, that is, no preincubation with $100 \mu \mathrm{M}$ ATP. (d) The Nercc1 protein kinase domain and RCC1 domain interact in vivo. HEK293 cells were transfected with the HA-Nercc1 protein kinase domain, HA-Nercc1(1-391), and either Flag-Nercc1 RCC1 domain, Flag-Nercc1(338778), or empty plasmid. Anti-Flag immunoprecipitates were immunoblotted with anti-HA (upper panel) or anti-Flag (middle panel). The expression of HA-Nercc1(1-391) is shown in the lower panel. A cartoon of the Nercc1 variant used in Figure 6 is below. 
spontaneous activation in vivo only if the C-terminal tail, that is, the ability to homodimerize, remains intact.

Although this model fits the data for Nerccl activation in vitro it is obvious that, inasmuch as the intracellular ATP concentration is $2 \mathrm{mM}$ to $5 \mathrm{mM}$, the low basal activity of recombinant and endogenous Nercc1 kinase must reflect the operation in vivo of one or more negative regulatory inputs, in addition to the inhibition provided by the RCC1-like domain. Such inputs could include protein phosphatases, as well as inhibitory ligands or polypeptides.

\section{Nercc1 binds to Ran}

The presence in Nerccl of a domain homologous to RCC1, a nucleotide exchange factor protein for the Ran GTPase, raises the question of whether Nerccl binds Ran, and if so, to what functional effect. Prokaryotic recombinant GST and GST fusions with the Nercc1 kinase domain-GST-Nercc1(1-391), the RCC1 domainGST-Nercc1(338-739), and the C-terminal tail-GSTNercc1(732-979) were immobilized on GSH-agarose beads and incubated with prokaryotic recombinant Ran that had been preloaded with GTP $\beta$ S or GTP $\gamma$ S. Whereas neither GST nor GST-Nercc1(732-979) bind Ran, the GST-Nerccl kinase domain and RCC1-like domain fusion proteins are able to bind Ran with very high efficiency (Fig. 5a). Both Nerccl domains bind Ran-GDP to a somewhat greater extent than Ran-GTP; however, the degree of this preference is somewhat variable between experiments.

To examine the interaction between Ran and Nercc1 in vivo, we coexpressed HA-wild-type Ran (wild type) with different Flag-Nerccl mutants, and probed the Flag immunoprecipitates for the presence of HA-wild-type Ran. Cell lysis and subsequent washes were carried out in the presence of excess $\mathrm{Mg}^{2+}$ to conserve Ran in its nucleotide-bound form. Figure $5 \mathrm{~b}$ shows that wild-type Ran associates with full-length Nerccl (both wild-type and $\mathrm{K} 81 \mathrm{M}$ ) as well as with the isolated Nerccl catalytic domain fragments, 1-308 and 1-391, as expected from Figure $5 \mathrm{a}$. The specificity of this interaction was assessed by examining the relative ability of Ran to bind the Nercc1 catalytic domain, Nercc1(1-308), or Nek 6, another protein kinase in the NIMA subfamily (Fig. 5c); no binding of HA-Ran to Nek6 is detectable, whereas both the Nercc1 catalytic domain and RCC1 (the Ran GEF, a positive control) bind avidly to Ran.

The deletion of the RCC1 domain, Nercc1( $\Delta 347-732)$, or the C-terminal tail, Nercc1(1-739), does not detectably impair the binding of HA-Ran, and in contrast to the in vitro results, the isolated Nercc1 RCC1-like domain, Nercc1(338-739), shows very little association with Ran. The inability of the Nercc1 RCC1 domain to bind Ran in vivo is as yet unexplained. The RCC1-like domain may simply bind Ran with lower affinity than the catalytic domain; conversely, access of Ran to the isolated Nercc1 RCC1-like domain in vivo may be obstructed.

We next addressed the relative binding in vivo of
Nercc1 to Ran-GDP versus Ran-GTP. A potential confounding element in assessing the interactions of Nerccl with the different forms of Ran in vivo is the subcellular localization of the various partners; in interphase cells Ran-GDP is located exclusively in the cytoplasm, whereas Ran-GTP is restricted to the nucleus (Kalab et al. 2002), a situation maintained by the nuclear location of the Ran GEF, RCC1, and the cytosolic localization of Ran GAP. We therefore coexpressed either full-length, wild-type Nercc1, which is exclusively cytoplasmic (see below) or a nuclear-targeted form of full-length Nercc1 (NLS-Nercc1) with wild-type Ran or Ran mutants that bind GDP (T24N) or GTP (G19V) exclusively; either Ran or Nercc1 was immunoprecipitated and probed for the association with the other polypeptide. Figure $5 \mathrm{~d}$ shows that full-length, wild-type Nercc1 binds coexpressed wild-type Ran and Ran T24N to a greater extent than RanG19V. Although this suggests a preference for RanGDP, it should be recalled that whereas RanT24N and Nerccl are both cytoplasmic, RanG19V is exclusively nuclear in localization. However NLS-Nercc1, which is exclusively nuclear (see Fig. 7c below), also does not bind the GTP-locked mutant RanG19V, strongly supporting the conclusion that full-length Nerccl indeed has a higher affinity for Ran-GDP over Ran-GTP.

The effect of Ran on Nerccl activation in vitro was examined by preincubation of Nerccl with $\mathrm{Mg}^{2+}$ and GST or GST-Ran, GST-Ran (GDP $\beta s$ ), or GST Ran (GMPPNP), and subsequent addition of $100 \mu \mathrm{M}$ ATP. No significant differences were observed in rate of activation or in the final activity (data not shown).

Nercc1 is phosphorylated and activated during mitosis and can be phosphorylated in vitro by $234^{C d c 2}$

We next examined Nerccl protein levels and activity during cell cycle progression. The level of Nerccl protein in HeLa cell extracts remains constant during different phases of the cell cycle $\left(G_{1} / S, G_{2}, M, G_{1}\right)$; however, the Nerccl polypeptide displays a marked slowing in electrophoretic mobility during mitosis (Fig. 6a), which can be mimicked by treatment in vivo with the protein phosphatase inhibitor calyculin (data not shown). A similar electrophoretic slowing of Nercc1 occurs in CHO-K1, COS7, U2OS, or HEK293 cells arrested in mitosis (data not shown). In addition to nocodazole-induced mitotic arrest, we also examined mitotic cells prepared by shakeoff from a culture that had been pseudosynchronized in $\mathrm{G}_{1} / \mathrm{S}$ by thymidine block and then released into the cell cycle (Fig. 6b). Nercc1 is unmistakably up-shifted in the mitotic cells, whether normally cycling or nocodazolearrested, establishing that the Nerccl modification is a characteristic of cells progressing normally through mitosis, rather than the result of activation of the spindle checkpoint. In further experiments we used mitotic no codazole-arrested cells as a model of normal mitotic cells.

Endogenous Nercc1 kinase activity was assayed in immunoprecipitates prepared from HeLa cells, comparing cells growing exponentially to cells treated with nocodazole; the latter were divided into those detached after 


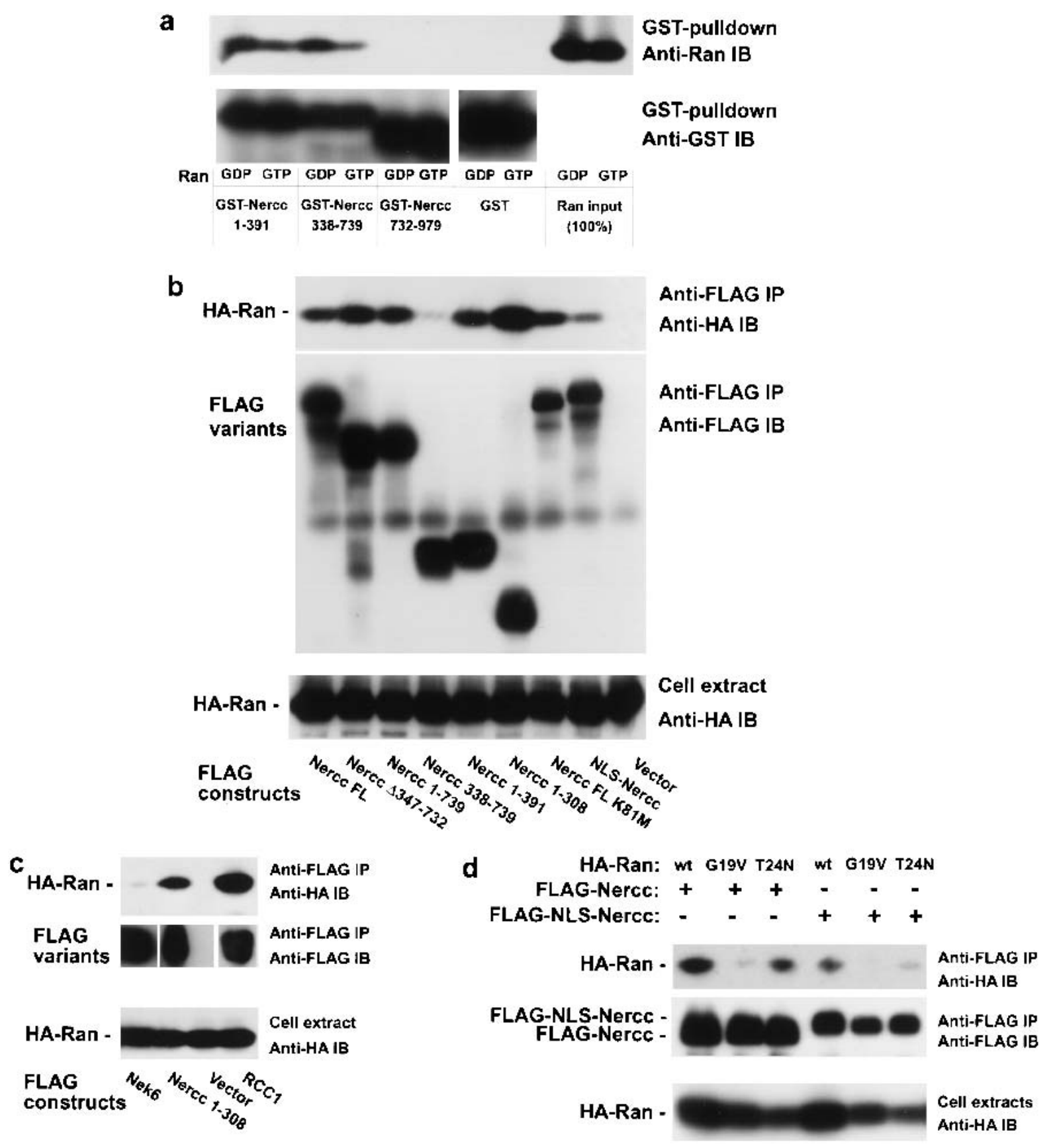

Figure 5. Nerccl binding to Ran. (a) The binding of recombinant Ran to GST-Nercc1 variants in vitro. GST and GST-Nercc1 variants were purified and immobilized on GSH-agarose. Ran was produced in bacteria as a GST fusion, purified, cleaved from the immobilized GST fusion, and loaded with GDP $\beta$ S (GDP) or GTP $\gamma$ S (GTP). Immobilized GST or GST-Nercc1 fusion proteins were incubated with Ran in the Ran binding buffer containing the indicated nucleotides $(100 \mu \mathrm{M})$. After extensive washing, the proteins retained on the GSH-agarose were eluted into SDS sample buffer, and analyzed by immunoblot for Flag (upper panel) and GST (lower panel). The Ran input is shown. $(b, c)$ HEK293 cells were cotransfected with HA-Ran and Flag-Nercc1 variants or Flag vector. Cells were extracted into Ran lysis buffer. Anti-Flag immunoprecipitates and aliquots of the extracts were subjected to immunoblot with anti-HA (upper panel) and anti-Flag (middle panel) antibodies. Expression of HA-Ran is shown in the lower panel. (d) HEK293 cells were transfected with Flag-Nercc1 (left) or Flag-NLS-Nercc1 (right) together with either HA-Ran wild type, HA-Ran G19V (constitutively GTP-bound), or HA-Ran T24N (constitutively GDP-bound or nucleotide-free). Cells were extracted into Ran lysis buffer. Anti-Flag immunoprecipitates were immunoblotted with anti-HA (upper panel) and anti-Flag (middle panel). The expression of the HA-Ran variants is shown in the lower panel. 
a

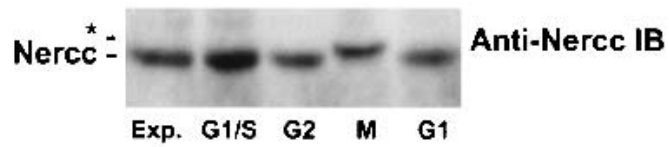

b

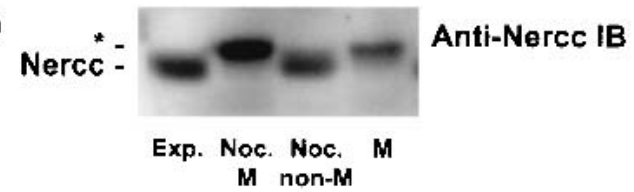

C

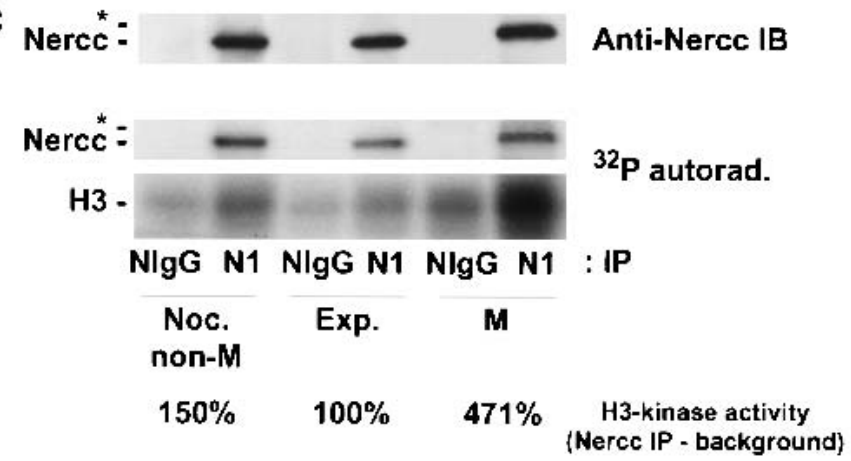

d

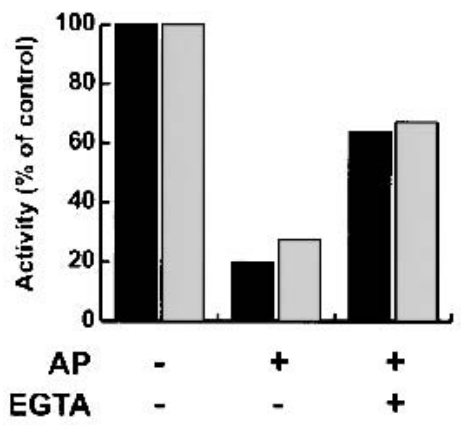

e

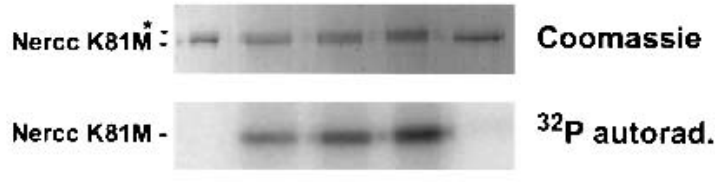

Figure 6. Nercc1 kinase is activated during mitosis and can be phosphorylated in vitro by p34 ${ }^{\text {Cdc2 }}$. $(a)$ HeLa cells were isolated in different phases of the cell cycle. $\left(G_{1} / S\right)$ Cells arrested with aphidicolin $(2 \mu \mathrm{g} / \mathrm{mL}$ overnight $) ;\left(G_{2} / M\right)$ cells arrested with aphidicolin and released for $6 h_{;}(M)$ mitotic cells isolated by shake-off from a culture treated with nocodazole $\left(500 \mathrm{ng} / \mathrm{mL}\right.$ overnight). $\left(\mathrm{G}_{1}\right)$ Mitotic cells, isolated as above, were washed repeatedly, replated, and harvested $6 \mathrm{~h}$ later. (Exp.) Exponentially growing cells. Each cell cycle stage designation was confirmed by FACS. An immunoblot of endogenous Nercc1 (C1 antibody) at the different cell cycle stages is shown. (b) Slowing of Nercc1 on SDS-PAGE occurs during normal progression through mitosis. HeLa cells were partially synchronized using thymidine ( $2 \mathrm{mM}$ thymidine overnight plus release). The resulting mitotic cells were collected by shake-off $9 \mathrm{~h}$ later and compared with exponentially growing cells (Exp.); mitotic, nocodazole-arrested cells detached after mitotic shake-off (Noc. M); and nocodazoletreated cells that remain attached after shake-off (non-mitotic cells; Noc. Non-M). Extracts of each cell type were subjected to immunoblot using anti-Nercc1 C1 antibody. (c) Nercc1 kinase is activated in mitosis. Immunoprecipitations were carried out using extracts from nocodazole-treated cells that remain attached after shake-off (non-mitotic cells; Noc. Non-M), exponentially growing cells (Exp.), or mitotic nocodazole-arrested cells (Noc. M), with both preimmune rabbit IgG (NIgG) and affinity-purified anti-Nercc1 antibody (N1). Immunoprecipitates were washed sequentially with lysis buffer and phosphorylation buffer, and incubated at $30^{\circ} \mathrm{C}$ for 10 min with $\mathrm{Mg}^{2+}$ plus $\left[\gamma_{-}{ }^{32} \mathrm{P}\right] \mathrm{ATP}(10 \mu \mathrm{M})$ and histone $\mathrm{H} 3(2 \mu \mathrm{g} / 50 \mu \mathrm{L})$. The reaction was stopped by addition of SDS sample buffer. Shown are an anti-Nercc1 (N1) immunoblot of the immunoprecipitates (upper panel) and the ${ }^{32} \mathrm{P}$ incorporation into Nercc1 (middle panel) and histone H3 (lower panel). ${ }^{32} \mathrm{P}$ incorporation into NIgG immunoprecipitates (background) was quantified by PhosphorImager and subtracted from $\mathrm{H} 3{ }^{32} \mathrm{P}$ incorporation in anti-Nercc1 immunoprecipitates. The resulting Nerccl activity was expressed as the percentage of activity in exponentially growing cells. (d) Flag-Nerccl preactivated by incubation with $100 \mu$ M ATP (black bars) and endogenous Nerccl immunoprecipitated from cells arrested in mitosis by nocodazole (gray bars) were incubated in alkaline phosphatase buffer with no addition (columns 1 and 2) or with $40 \mathrm{U}$ of calf intestine alkaline phosphatase (columns 3-6), without (columns 3,4 ) or with (columns 5, 6) 4 mM EGTA. After washing, Nerccl activity was assayed and expressed as a percentage of non-phosphatasetreated enzyme (columns 1 and 2). (e) Nercc1 is an in vitro substrate of p34 ${ }^{\mathrm{Cdc} 2}$. Flag-Nercc1 K81M was produced in HEK293 cells, immunopurified with anti-Flag antibody, and eluted from the immunoprecipitates with Flag peptide. Soluble K81M was incubated at $30^{\circ} \mathrm{C}$ for the indicated times in phosphorylation buffer containing $100 \mu \mathrm{M}\left[\gamma_{-}{ }^{32} \mathrm{P}\right] \mathrm{ATP}$ with and without purified active p34 ${ }^{\mathrm{Cdc} 2} / \mathrm{cyclin}$ B from Xenopus MPF (maturation promoting factor). Coomassie staining and ${ }^{32} \mathrm{P}$ autoradiography of Nercc1 K81M are shown. Quantitation of incorporated ${ }^{32} \mathrm{P}$ into Nercc1 K81M was carried out by PhosphorImager.

mitotic shake-off (mitotic cells) versus those that remain attached (non-mitotic cells). The Nerccl kinase activity in mitotic cells is fourfold to fivefold higher than in exponentially growing cells, despite comparable polypeptide levels; nocodazole-arrested, non-mitotic cells show a small increase in Nerccl kinase activity, probably caused by contaminating mitotic cells (Fig. 6c). Similar results were obtained with U2OS cells (data not shown). Thus, Nerccl is activated during mitosis.

To determine whether the observed mitotic Nercc1 activation and change in electrophoretical mobility were caused by phosphorylation, we incubated Nerccl immunopurified from mitotic cells with phosphatase. As a control, recombinant Flag-Nercc1 preactivated by incubation with $100 \mu \mathrm{M}$ ATP was also treated with phosphatase (Fig. 6d). Phosphatase treatment increases FlagNerccl electrophoretical mobility, and simultaneously reduces Nerccl protein kinase activity against exogenous substrates, showing that Nerccl activity depends on phosphorylation. When endogenous mitotic Nercc1 
was incubated with phosphatase, a similar decrease in protein kinase activity was observed. Thus, Nerccl activation in vitro and in vivo during mitosis is caused by phosphorylation.

Transiently expressed, catalytically inactive forms of recombinant Nercc1 (K81M or 338-979) show an upshift on SDS PAGE in response to nocodazole, much the same as wild-type Nerccl (data not shown). Such inactive Nercc1 mutants cannot autophosphorylate, indicating that the mitotic modification of Nerccl at least in part is owing to another protein kinase; an obvious candidate is $\mathrm{p} 34^{\mathrm{Cdc} 2}$. Recombinant full-length Flag-Nercc1 (K81M) eluted from Flag-agarose beads is phosphorylated in vitro by purified Xenopus active p34 ${ }^{\mathrm{Cdc} 2} /$ cyclin B (maturation promoting factor, MPF; Fig. 6e). MPF-catalyzed Nercc1 phosphorylation induces an up-shift in Nercc1 similar to that observed in vivo in mitotic cells, and overall ${ }^{32} \mathrm{P}$ incorporation into Nercc1 (K81M) rapidly approaches 1 mole $\mathrm{PO}_{4} /$ mole protein (Fig. 6e). Similar results are obtained with cyclin $\mathrm{B}$ immunoprecipitates from nocodazole-arrested mitotic HeLa cells, whereas cyclin B immunoprecipitates from non-mitotic cells do not catalyze Nercc1 phosphorylation (data not shown). Inhibition of the Nercc1-phosphorylating activity in the cyclin B immunoprecipitate from mitotic cells by the CDK inhibitor roscovitine confirms the identity of the kinase activity as Cdc2. Thus, Nercc1 is an in vitro substrate for $\mathrm{p} 34^{\mathrm{Cdc} 2}$, and this phosphorylation produces a change in Nercc1 electrophoretic mobility similar to that observed in mitotic cells, indicating that $\mathrm{p} 34^{\mathrm{Cdc} 2}$ contributes to Nercc1 phosphorylation during mitosis.

It is important to point out that phosphorylation of Nercc 1 by Cdc2/MPF in vitro does not significantly alter maximal Nercc1 kinase activity toward histone $\mathrm{H} 3$. Similarly, the up-shift in Nerccl mobility that occurs on treatment of cells with calyculin is not accompanied by an increase in Nerccl kinase activity (data not shown). Thus, although the autophosphorylation/autoactivation of Nerccl in vitro is also accompanied by a slowing in electrophoretic mobility, the occurrence of an up-shift is not synonymous with Nercc1 activation. The functional consequences of Cdc2-catalyzed phosphorylation of Nerccl during mitosis are not yet known.

\section{Nercc1 cellular localization}

Immunofluorescence studies using the N1 or C1 antiNerccl peptide antibodies showed Nerccl to have a finely granular cytoplasmic fluorescence in all cell lines tested (HeLa, PtK2, HEK293, NIH3T3). Nercc1 appears distributed diffusely in the cytoplasm without association with organelles, plasma membrane, or cytoskeletal elements (Fig. 7a; see also Supplemental Fig. 3). We also performed nonequilibrium sucrose density gradient fractionation of HEK293 cells; Nercc1 sedimentation corresponded to that of other cytoplasmatic proteins (e.g., lactate dehydrogenase), and was distinct from a variety of membrane markers, for example, $\beta C O P$, a TGN marker. Overlay of Nercc1-enriched fractions with lighter sucrose followed by centrifugation to equilibrium did not result in Nerccl translocation up into the low-density fraction, as occurs with membrane-bound proteins /data not shown). Thus Nerccl is localized in the cytoplasm unattached to cellular membranes.

Notably, Nerccl immunoreactivity is absent from the nucleus (Fig. 7a). The lack of nuclear Nercc1 was also evident on overexpression of recombinant Flag-Nercc1 (Fig. 7c; Supplemental Fig. 3). This was surprising, as Nerccl contains a classical nuclear localization signal (NLS) that is fully functional when appended to the Nercc1 $\mathrm{N}$ terminus or to another polypeptide (Fig. 7c). Careful examination of immunofluorescence specimens of cells subjected to a variety of treatments including leptomycin B, an inhibitor of CRM-dependent nuclear export (Supplemental Fig. 3), failed to uncover instances of endogenous Nerccl in nuclei.

We next examined Nerccl localization in mitotic cells (Fig. 7b). HeLa cells were blocked in mitosis with nocodazole, or enriched in mitotic cells by double thymidine block followed by release and mitotic shake-off; in both instances, Nercc1 immunofluorescence in mitotic cells was diffusely distributed throughout the cell and conspicuously absent from the chromosomes. To test whether Nerccl is associated with the mitotic spindle, mitotic HeLa cells were fixed after treatment for $1 \mathrm{~min}$ with the nonionic detergent saponin. Eg5, a microtubule-binding motor, is readily visualized on spindle microtubules after this light saponin treatment, whereas endogenous Nerccl immunofluorescence is completely removed from the cells under these conditions. Thus Nerccl is not (tightly) associated with the spindle microtubules, and is diffusely distributed through the cell during mitosis.

A series of Flag-Nercc1 mutants was examined for their cellular distribution during transient expression in HeLa cells (Fig. 7c). Four types of subcellular distribution were observed: cytoplasmic, nucleocytoplasmic, predominantly nuclear, and exclusively nuclear. Overexpressed wild-type Nercc1 is distributed in the cytoplasm like endogenous Nercc1; however, $\sim 5 \%$ of cells show slight nuclear immunofluorescence. The inactive Nercc1 ATP-site mutant (K81M) shows a substantial nuclear component, suggesting that the NLS might be inactivated by autophosphorylation. The Nercc1(1-391) variant, although potentially capable of being activated, is nevertheless exclusively nuclear; this establishes the functionality of the Nercc1 NLS, as does the exclusive nuclear localization of a wild-type Nerccl to which a copy of its endogenous NLS is fused at its $\mathrm{N}$ terminus.

The conversion of Nerccl to forms that achieve nuclear localization results in the frequent occurrence of micronuclei, multiple nuclei, and lobed nuclear morphologies. Such phenotypes have been associated in other circumstances with lagging chromosomes and chromosome nondisjunction in anaphase (Cimini et al. 2001). The frequency of these morphologies was highest in cells expressing Nercc1(1-391), that is, an active kinase domain with the nuclear localization; however, expression of the cytoplasmic kinase-inactive variant Nercc1(1-739), as well as the nuclear/cytoplasmic vari- 
a

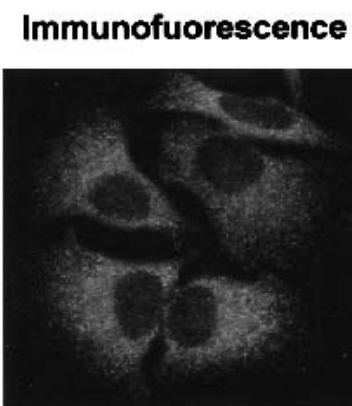

b

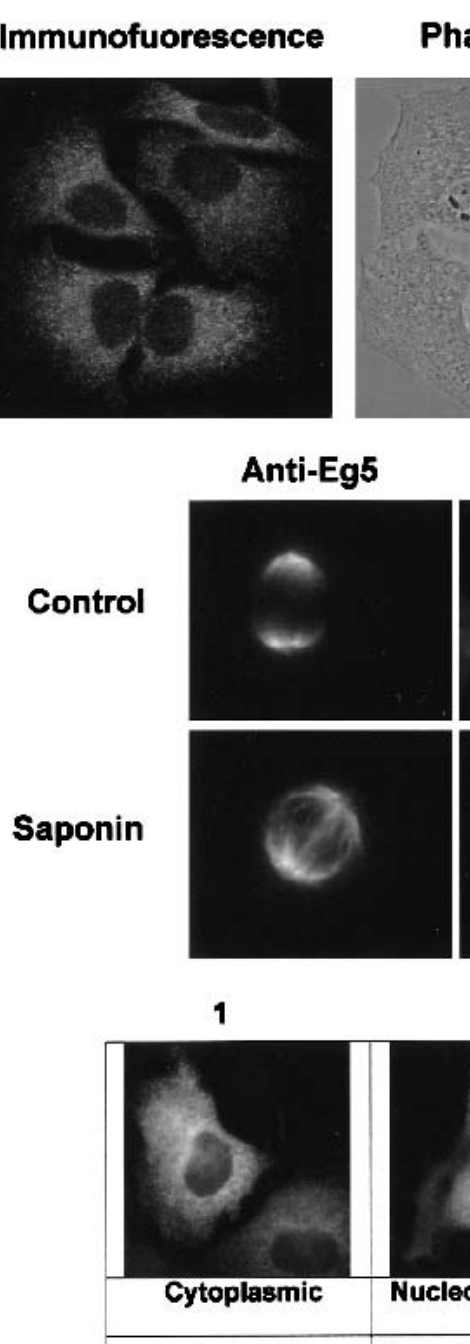

1

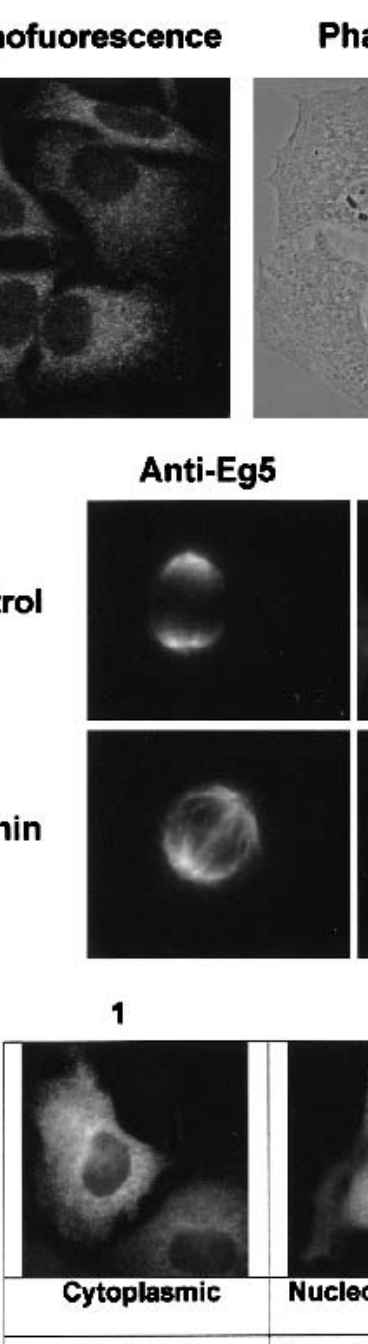

Cytoplasmic

\begin{tabular}{|c|c|c|c|c|}
\hline & & nuciear & & inorpnologies \\
\hline WINASE KLLS RCCI- & - KIIASES & KIMABE & FINASE NAS. & 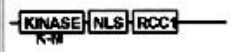 \\
\hline 世MA8E & & - KGNASE NLS & NLS ENASE NLS BCG - & WOMASE MLS RCC \\
\hline EIINASE NLS & & - & WLS KOASE, WLS & KAMasE HLS. \\
\hline HCCA- & & HLS & & KINASA \\
\hline Fac & & 뇨 ROCC & & \\
\hline
\end{tabular}

Figure 7. Nercc1 cellular localization. (a) Nercc1 immunolocalization in interphase. Specificity of the anti-Nercc1 C1 antibody. Cells were immunostained as described, using anti-Nerccl C1 antibody (left panels) or the $\mathrm{Cl}$ antibody preincubated with the immunizing peptide (right panels). Bar, $10 \mu \mathrm{m}$. (b) Immunocytochemical identification of Eg5, Nercc1, and DNA in mitotic HeLa cells, before and after a light (1-min) saponin treatment. Bar, $10 \mu \mathrm{m}$. (c) Flag-Nercc1 variants were transfected into HeLa cells, and their localization was visualized using anti-Flag antibody. The subcellular distribution of Flag-Nercc1 was assessed and assigned to four subgroups: cytoplasmic, nucleocytoplasmic, predominantly nuclear, and nuclear. Variants that induced abnormal nuclear morphologies are shown in panel 5; an example of the lobed nuclear morphology observed with several variants is shown.

ants, Nercc1 (K81M) and Nercc1(1-308) have a similar, but less marked effect (Fig. 7c, column 5).

\section{Nercc1 regulates mitotic progression}

The structural similarities between Nercc1 and NIMA, the activation of Nerccl during mitosis, the ability of
Nerccl to bind Ran in vitro and in vivo and to induce abnormal nuclear morphology when targeted to the nucleus, together point to the likelihood that Nerccl is a mitotic regulator. A preliminary indication was provided by the observation that transfection of a plasmid encoding an eGFP-Nercc1 (K81M) fusion protein appeared to interdict cell division. Thus, time-lapse recordings of 
transfected HeLa cells showed that, whereas $78 \%$ of 70 cells transfected with a plasmid encoding eGFP alone underwent division within the subsequent $36 \mathrm{~h}$, only $4 \%$ of $52 \mathrm{HeLa}$ cells transfected with eGFP-Nercc1 (K81M) underwent division, and $85 \%$ proceeded to cell death as compared with $18 \%$ of the eGFP-transfected cells. Interestingly, even wild-type Nercc1 was somewhat toxiconly $29 \%$ of $31 \mathrm{HeLa}$ cells transfected with an eGFPNercc1 plasmid proceeded through mitosis. The impact of the nuclear-localized Nercc1(1-391) was even more marked; only 1 of $45 \mathrm{HeLa}$ cells transfected with eGFP-Nercc1(1-391) underwent division, and $72 \%$ of these cells were dead after $36 \mathrm{~h}$.

To test directly whether Nerccl participates in the control of mitotic progression, we used live observation of PtK2 cells after microinjection of affinity-purified anti-Nerccl (peptide) antibodies or purified preimmune IgG. When Ptk2 cells were injected with Nercc1 antibodies during interphase, mitosis was never subsequently observed, preventing any conclusion. Therefore, antibody microinjection of cells in prophase was undertaken; such cells were identified by the presence of chromosome condensation and nucleolar disassembly. All such cells microinjected with normal rabbit IgG (5 at 2.5 $\mathrm{mg} / \mathrm{mL}$ and 15 at $10 \mathrm{mg} / \mathrm{mL}$ ) completed mitosis normally and produced daughter cells, save one, which had a lagging chromosome; this occurrence is consistent with the frequency of lagging chromosomes reported earlier for PtK cells (Izzo et al. 1998). In contrast, 14 cells of 30 cells (i.e., roughly $45 \%$ ) microinjected with affinitypurified anti-Nercc1 (C1) IgG $(2.5 \mathrm{mg} / \mathrm{mL})$ showed mitotic abnormalities of two basic types. The first type involved abnormalities in chromosomal segregation associated with abnormal spindle dynamics. Thus, four cells never entered anaphase B (i.e., movement of poles with attached chromosomes in opposite directions), although the spindle was apparently normal; nevertheless, cytokinesis proceeded. In two experiments this resulted in the subsequent trapping of one or more chromosomes in the cytokinetic furrow, creating DNA bridges between the nuclei of daughter cells (Fig. 8a, left column, A). In two other cases, separation of the chromosomes to opposite poles stopped prematurely, chromosome decondensation was observed, and a cytokinetic furrow formed to one side of the spindle, resulting in formation of one daughter cell with 4N DNA and one daughter cell without DNA (Fig. 8a, middle column, B). The second type of abnormality concerned the formation of the mitotic spindle. In eight cells, the spindle was not visible on phase contrast images throughout the whole duration of the recording, and $\sim 40 \mathrm{~min}$ after the nuclear envelope breakdown, the chromosomes concentrated in the center of the rounded-up PtK2 cell, with chromosome arms extending far into the cell periphery (Fig. 8a, right column, C). When fixed immediately after the recording, these cells showed a highly disrupted spindle (Fig. 8b, antiNercc1; cf. with a cell microinjected with control IgG, control); although two separated centrosomes were visible, the cells showed an interphase array of microtubules.
Two anti-Nercc1 C1-microinjected cells formed a bipolar mitotic spindle, but anaphase started prematurely, specifically at only $8 \mathrm{~min}$ after the last monooriented chromosome acquired biorientation (this is $1 \mathrm{~min}$ less than the minimum time recorded for PtK cells; Rieder et al. 1994). Thus, in these cells, anaphase started without congression of chromosomes to the metaphase plate, although cell division proceeded normally from then on (data not shown).

Similar kinds of mitotic abnormalities, including a failure to enter anaphase B, were observed in 4 of 8 cells microinjected with an anti-Nerccl IgG raised against a peptide sequence from the Nercc1 catalytic domain (E2 antibody, amino acids 80-94). Microinjection of 10 Ptk2cells with affinity-purified anti-Nercc1 N1 (amino acids 3-18) IgG did not alter the normal progression of mitosis (data not shown).

We also microinjected the Nerccl C terminus antibody into CF-PAC1 cells in prophase. CF-PAC1 cells are a human cell line that contains levels of Nerccl comparable to HeLa and HEK293 cells (data not shown) and that has been used previously for microinjection studies of spindle dynamics (Mountain et al. 1999). Three out of five microinjected cells arrested in prometaphase for 3-10 h with several monooriented chromosomes close to the spindle poles (Fig. 8c, arrows); all five control cells microinjected with normal rabbit IgG showed normal mitosis. Among five CF-PAC1 cells microinjected early in prometaphase with anti-Nerccl antibody, only one showed a similar mitotic defect, whereas the other four proceeded through mitosis normally.

The occurrence of similar mitotic abnormalities in Ptk2 cells microinjected with two independently prepared anti-Nerccl antibodies, raised against different Nerccl peptides, and the absence of these phenotypes in response to nonimmune IgG, together with the occurrence of similar abnormalities in CF-PAC1 cells indicate strongly that interference with Nerccl is the basis for these phenotypes. In summary, microinjection of antiNercc1 (C-terminal peptide) C1 IgG and anti-Nercc1 (catalytic domain peptide) E2 IgG results in the frequent occurrence of abnormal spindle dynamics and abnormal chromosomal congression and segregation, indicating that Nerccl ordinarily participates in the regulation of these processes.

\section{Discussion}

\section{Nercc1 kinase is a novel mitotic regulator}

The Nerccl kinase is a new member of the mammalian branch of the NIMA-like kinases. Perhaps the most consequential aspect of this work is the clear-cut demonstration that Nercc1, like NIMA, is a pleiotropic regulator of mitotic progression, participating in the control of spindle dynamics and chromosome separation. Among the previously characterized mammalian kinases with NIMA-like catalytic domains, only Nek2 has been shown to be clearly involved in any aspect of mitotic regulation, that is, centrosome separation. Although 
mammalian cells were shown to respond to NIMA overexpression with chromatin condensation and are blocked in $\mathrm{G}_{2}$ by different nonfunctional versions of NIMA, it has not previously been clear whether functional homologs of NIMA exist in metazoans (O'Connell et al. 1994; Lu and Hunter 1995). None of the described mammalian enzymes with protein kinase domains homologous to NIMA (Nek1-7; Nigg 2001) appears to have functions similar to that of Aspergillus NIMA, that is, control of the $\mathrm{G}_{2} / \mathrm{M}$ transition (Osmani et al. 1991a; Lu and Means 1994), chromosome condensation (Osmani et al. 1988b; O'Connell et al. 1994), and spindle and nuclear envelope organization during and after mitosis (Osmani et al. 1991b).

We show that microinjection of interfering antiNercc1 IgGs into PtK2 and CF-PAC1 cells in prophase induces several types of abnormalities. Many Ptk2 cells microinjected with anti-Nerccl antibody arrest in prometaphase without an observable spindle. Other cells show a bipolar spindle, but defective chromosome orientation and segregation result in aneuploidy after cytokinesis. In a few cells, spindle separation is markedly defective, but cytokinesis proceeds, resulting in the sequestration of the entire spindle and 4N DNA content into only one of the daughter cells. CF-PAC1 cells microinjected in prophase with anti-Nerccl antibody also show abnormalities in chromosome attachment, but in contrast to Ptk2 cells, CF-PAC1 cells microinjected with anti-Nerccl antibody in prophase arrest in prometaphase with monooriented chromosomes.

Inasmuch as these IgG injections were made after chromosome condensation, we have no direct evidence concerning the participation of Nerccl in this or other earlier steps in $\mathrm{G}_{2} / \mathrm{M}$ progression. Nevertheless, overexpression of nuclear forms of Nerccl, especially Nercc1(1-391) and Nercc1(1-308), produce markedly abnormal morphologies of the interphase nucleus (Fig. 7c), and these Nercc1 variants collect at peripheral sites near the tips of lobed nuclei. The basis for this appearance is unknown, and its relationship to NIMA-induced chromosomal condensation in mammalian cells will probably require a side-by-side comparison.

The molecular basis for the abnormalities observed when anti-Nercc1 IgG is introduced into mitotic cells is not known. The phenotypes suggest possible roles for Nercc1 in spindle assembly and dynamics as well as in chromosome attachment, alignment at the spindle midzone, and segregation. The occurrence of arrest in prometaphase suggests activation of the spindle checkpoint, whereas the instances in which mitotic progression of antibody-microinjected Ptk2 cells continues through anaphase and cytokinesis despite chromosome misalignment and maldistribution indicate that the metaphaseanaphase and mitotic exit checkpoints have been bypassed. A possible explanation is that Nerccl regulates one or more components of the cell cycle machinery involved in both spindle formation and checkpoint action. Motor proteins have this characteristic and are thus good candidates to be targets for Nercc1 (Brunet and Vernos 2001).
In addition to possible functional homology, Nercc1 has a striking number of structural similarities with NIMA aside from their homologous catalytic domains. Nercc1 has a C-terminal tail containing an NLS, a substantial set of S/TP sites, several PEST regions, and a coiled coil that serves as a homooligomerization motif. In addition, Nercc1 is an in vitro substrate of $\mathrm{p} 34^{\mathrm{Cdc} 2}$ and shows increased activity during mitosis. Nevertheless, Nercc1 also displays some remarkable differences from NIMA, the most conspicuous being the presence of a domain homologous to RCC1 and the ability to bind Ran. Also, whereas NIMA is localized to the nucleus and its levels change greatly during cell cycle progression, Nercc1 is cytoplasmic in interphase and its protein levels do not appear to change during the cell cycle. Thus, it is highly unlikely that Nerccl is an exact mammalian equivalent of NIMA. More likely, the numerous functions of NIMA characterized in Aspergillus have been parsed out among a number of kinases in mammalian cells, which differ in regulation and perhaps specificity; Nercc1 certainly appears to be one of these.

In this regard, the association of Nercc1 with Nek6 and Nek7 (data not shown) requires comment. The tight association of Nerccl with these two kinases suggests that they represent elements in a signal transduction cascade or a linked effector unit or possibly both. Apart from the role of Nek6/7 as a candidate p70 S6 kinasekinase (Belham et al. 2001), the cellular responses to Nek6/7 are as yet uncharacterized. When extracted after transient expression in normally cycling cells, Nek 6/7 shows considerable basal activity, in contrast to Nercc1. We showed previously that the spontaneous activity of recombinant Nek6 is reversed by protein phosphatase treatment in vitro. Preliminary experiments indicate that Nerccl is capable of phosphorylating and activating Nek7 in vitro. It is therefore conceivable that some or all of the phenotypes observed on microinjection of interfering anti Nercc1 IgG are caused by interference with Nek6/7 function.

\section{Regulation of Nercc1 kinase function}

Our analysis thus far of the regulation of Nercc1 activity indicates that in vitro, the recombinant Nerccl polypeptide is a homooligomer that is maintained in an inactive state by occlusion of its catalytic domain by the succeeding RCC1-like domain; this inhibition may occur either in cis or in trans within the dimer. The monomeric variant Nercc1(1-739) also has low activity and is almost entirely resistant to autoactivation in vitro by $\mathrm{Mg}^{2+}$ plus ATP. The further deletion of the RCC1-like domain produces Nercc1(1-391); this variant also shows low basal activity but is capable of significantly greater autoactivation in the presence of $\mathrm{Mg}^{2+}$-ATP than is Nercc1/1739), although at rates far below wild type. In contrast, a deletion of the RCC1-like domain that leaves the Nercc1 dimer intact, that is, Nercc1( $\Delta 347-732)$, shows very high basal activity, either through spontaneous activation in vivo, or essentially instantaneous autoactivation in vitro upon addition of $\mathrm{Mg}^{2+}$-ATP. The very strong dependence 
a
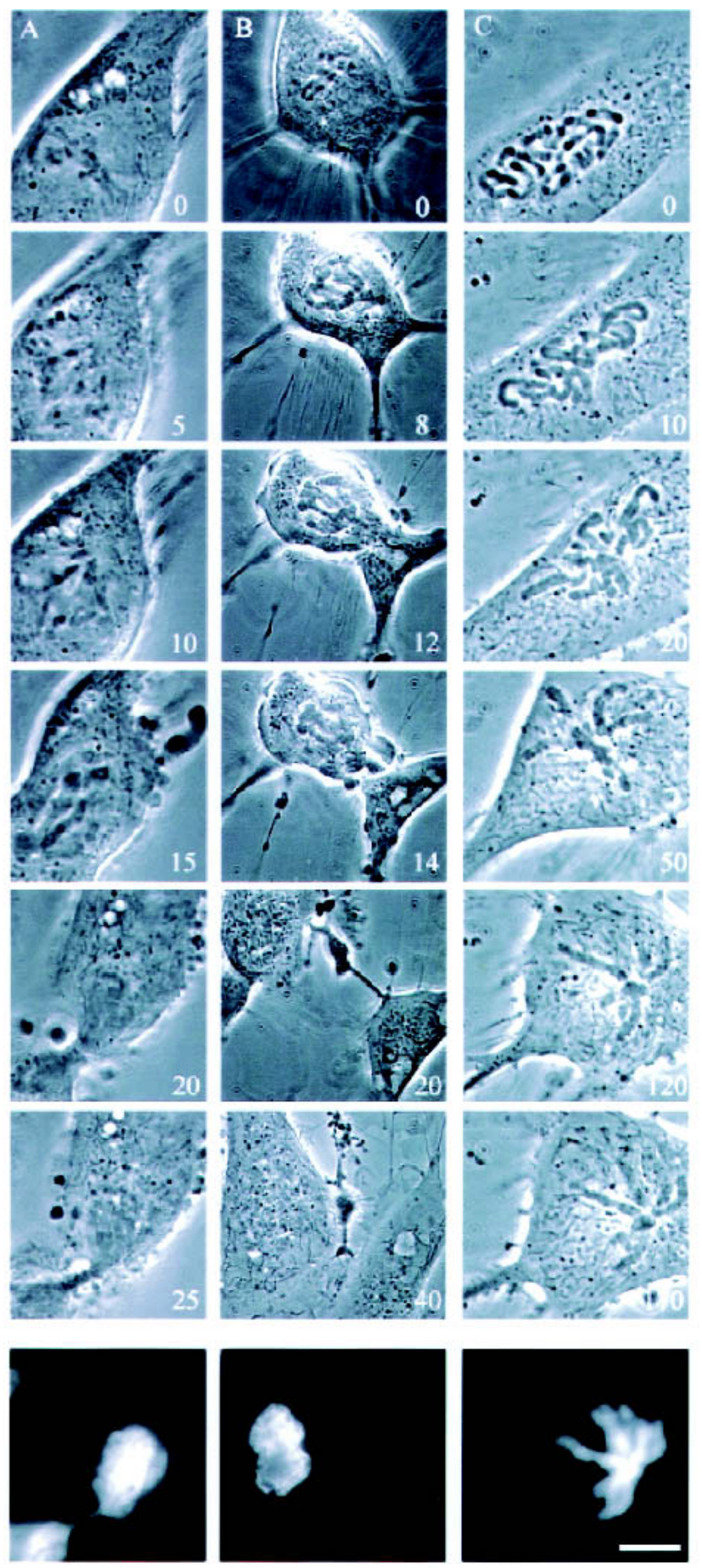

b
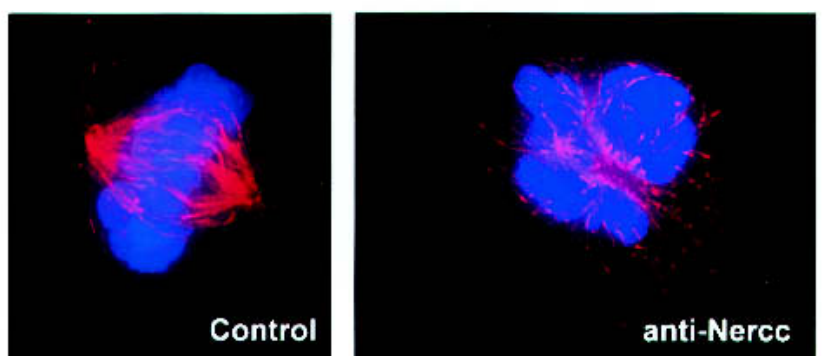

c
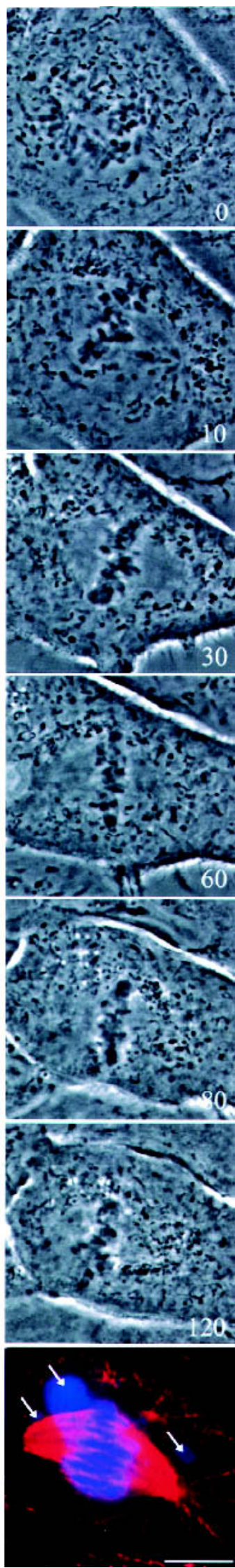
on oligomerization and $\mathrm{Mg}^{2+}$-ATP for activation in vitro points to intramolecular trans-phosphorylation of the Nercc1 activation loop as the likely basis for activation in vivo.

In view of the spontaneous autoactivation of Nerccl in vitro in the presence of $\mathrm{Mg}^{2+}$-ATP, the finding that both endogenous and recombinant Nerccl are extracted from cycling cells in a low activity state indicates that one or more powerful exogenous negative regulatory inputs act on Nercc1 during interphase. In addition, the substantial increase in the specific activity of endogenous Nercc1 seen in mitosis suggests the occurrence of a mitosis-specific loss of one or more of these inhibitory influences. One obvious set of candidates for such an inhibitor is the cytoplasmic Ser/Thr phosphatases, which may simply reverse Nerccl autophosphorylation. Nevertheless, calyculin A treatment of cells, although causing Nercc1 hyperphosphorylation, as reflected by a slowing in electrophoretic mobility, does not result in the activation of Nerccl kinase activity. Consequently, we infer that Nercc1 autophosphorylation must be maintained at a very low level during interphase. The rigidly cytoplasmic localization of Nercc1 during interphase may be important not only to prevent inappropriate access of Nercc1 to nuclear targets, but also for maintaining Nerccl in an inhibited state, probably through the binding of Nerccl to a cytoplasmic inhibitor. Nevertheless, simply targeting Nerccl to the nucleus, for example, by fusing an NLS to the Nercc1 N terminus, does not result in Nerccl activation. Thus we infer that the disinhibition/activation of Nercc1 depends on the availability of elements that appear as cells progress from $G_{2}$ into $M$. We have thus far identified two elements that interact with Nercc1, and whose availability is known to change with this phase of the cell cycle, namely, cyclin B/Cdc2, which can phosphorylate Nerccl to a considerable extent in vitro, and the small GTPase Ran. Phosphorylation of Nercc1 by MPF does not alter the maximal Nercc1 activity attainable after autophosphorylation, and in preliminary experiments does not appear to alter the rate of Nerccl autoactivation in vitro, although the latter conclusion is as yet tentative given the technical difficulties of those experiments. In addition, we have not yet determined whether MPF-catalyzed Nercc1 phosphorylation alters Nercc1 binding to its known interactors, Ran and Nek6/7.

As to the interactions of Ran with Nercc1, our in vitro assays do not as yet show any major impact of Ran on the rate of Nercc1 autoactivation. Nevertheless, we are intrigued by the specific and relatively tight binding of Ran to the Nerccl catalytic domain in vitro and in vivo, as well as the important role of the Nercc1 RCC1-like domain as a negative regulatory element. The Nercc1 RCC1-like domain also binds Ran specifically, although less tightly than the Nerccl catalytic domain.

Although other proteins have been described with domains similar to RCC1 (e.g., Herc 1-3; Rosa et al. 1996; Guo et al. 1998; Ji et al. 1999), that of Nercc1 is, to our knowledge, the first example of an RCC1-like domain (other than the RCC1 itself) shown to bind Ran. We have not yet determined whether the Nercc1 RCC1-like domain has any GEF activity toward Ran, although based on sequence comparison we think this highly improbable (see Fig. 1c). Moreover, a Ran GEF with a diffuse cytoplasmic distribution would certainly disrupt the RanGDP/RanGTP gradient that drives the nucleocytoplasmatic transport in interphase.

As to the possible role of Ran in the regulation of Nercc1, we offer the following speculations. Given the exclusive cytoplasmic localization of Ran-GDP in interphase and its very high concentration $1 \sim 1 \%$ of HeLa cell protein), as well as the preferential binding of Nerccl to Ran-GDP (Fig. 5d), we propose that Ran-GDP, acting together with one or more as yet unidentified elements, plays a role in maintaining the inhibited state of Nercc1 in interphase cells. During mitosis, with dissolution of the nuclear membrane, Ran assumes new functions. Recent work has established that in mitosis, as in interphase, the capacity of the RCC1-GEF/Ran system to serve as a positional marker continues to be used,

Figure 8. The effect of microinjection of anti-Nercc1 IgG into PtK2 and CF-PAC1 cells. $(a)$ PtK2 cells were microinjected with affinity-purified anti-Nercc1 (C1) IgG $(2.5 \mathrm{mg} / \mathrm{mL}$; typically, the volume of microinjected material comprised $\sim 10 \%$ of cell volume) in prophase. Representative phase contrast images from time-lapse recordings are shown. Recorded cells were fixed 3 min after the last image in the sequence shown and stained with Hoechst 33342 DNA stain (lowest image in each panel). Time in minutes is shown in the lower right-hand corner of the images, with acquisition of the last frame before the onset of anaphase serving as time $0(A, B)$. The first image in panel $C$ was taken 2 min after the nuclear envelope breakdown. Bar, $10 \mu \mathrm{m}$. (A) Anaphase A starts and proceeds normally, but the poles do not separate. Chromosomes remain trapped in the cytokinetic furrow and a bridge of DNA remains between the daughter cells. $(B)$ An example of an extreme case of the absence of anaphase B phenotype. After moving the chromosomes apart in anaphase A, the substantial further separation typical of anaphase B does not occur, and a cytokinetic furrow separates the daughter cells into one containing all chromosomes and a cytoplast. Hoechst staining confirms the absence of DNA in the right cell. (C) After the nuclear envelope breakdown, the cell fails to form a mitotic spindle, or the spindle collapses soon after formation. Mitotic progression stops in prometaphase. See $b$. (b) Ptk2 cells were microinjected with normal IgG (Control) or anti-Nercc1 (C1) IgG (anti-Nercc) in prophase. Cells were fixed and stained with Hoechst 33342 DNA (blue), and anti-tubulin antibody (red). Control cells were fixed at metaphase; anti-Nerccl injected cells failed to enter a normal metaphase, and were fixed at $t=120$ min after microinjection. (c) CF-PAC1 cells were microinjected with affinity-purified anti-Nercc1 (C1) IgG in prophase. Representative phase contrast images from a time-lapse recording are shown. The recorded cell was fixed $3 \mathrm{~min}$ after the last image in the sequence shown and stained with Hoechst 33342 DNA stain and anti-tubulin (lowest image). Time after antibody microinjection in minutes is shown in the lower right-hand corner of the images ( $t=0$ taken 2 min after nuclear envelope breakdown). Arrows show monooriented chromosomes. Bar, $10 \mu \mathrm{m}$. 
through the focal generation of Ran-GTP in the vicinity of the chromosome-bound GEF; this generation of RanGTP is critical in directing the construction of the mitotic spindle as well as in the reassembly of the nuclear envelope after telophase (Azuma et al. 1999; Hetzer et al. 2000). The gradient of Ran-GTP formed around the chromosomes by the action of RCC1 (Kalab et al. 2002) controls microtubule polymerization and motor activity and thus promotes aster formation and spindle assembly around chromosomes (for reviews, see Kahana and Cleveland 1999; Heald and Weis 2000). The mechanism through which Ran controls microtubule polymerization is similar to that of nucleocytoplasmic transport: binding of Ran-GTP to importins frees and activates different aster-promoting activities that are inactivated by importin binding (for reviews, see Dasso 2001; Walczak 2001). How Ran controls other steps involved in aster formation and spindle assembly (e.g., the activity of motor proteins like Eg5) and nuclear envelope formation, or whether Ran controls other aspects of mitosis is presently unknown (for a review on Ran and cell cycle control, see Moore 2001). Based on the phenotypes elicited by microinjection of anti-Nercc1 IgG into mitotic cells, and the ability of Nerccl to bind Ran, we propose that the activation of Nercc1 during mitosis /which is ultimately caused by the intramolecular transphosphorylation of the Nerccl activation loop) and/or the execution of its cellular functions will prove to involve the displacement of Ran-GDP in the vicinity of the chromosomes; this implies that although diffusely distributed, Nercc 1 is activated and/or acts primarily in the vicinity of the chromosomes. Certainly the control of protein kinase localization and activation by small GTPases, as first shown for Ras and Raf, is now recognized as a general regulatory mechanism in the regulation of protein kinase function. Reconstituting in vitro the apparatus underlying the cell cycle-dependent regulation of Nercc1 activity will be a substantial challenge.

In conclusion, Nerccl is a mammalian NIMA-like kinase that acts as a regulator of spindle function and chromosome segregation. Nerccl is tightly bound to another NIMA-like protein kinase, Nek6/7; the contribution of each kinase to the function of the other is as yet unknown. Nerccl is activated in mitosis by disinhibition and intramolecular autophosphorylation. It is a target for cyclinB/Cdc2 and binds specifically to the Ran GTPase through its catalytic and novel RCC1-like domain. The significance of Cdc2 phosphorylation and Ran binding in Nerccl activation, targeting, and function, as well as the immediate cellular substrates of Nercc1 await discovery.

\section{Materials and methods}

\section{Protein sequencing, cDNA cloning and manipulation}

The cloning of the Nercc1 cDNA and the construction of the different DNA plasmids used in this work is described in the Supplemental Material (available online at http://www.genesdev.org).

\section{Cell culture and transfection}

See Supplemental Material (available online at http://www. genesdev.org).

Cell lysis, immunoprecipitation, in vitro binding, and immunoblotting

Cells were rinsed with PBS, flash-frozen in liquid nitrogen, and stored at $-70^{\circ} \mathrm{C}$. Cell lysis used a buffer containing: $50 \mathrm{mM}$ Tris $(\mathrm{pH}$ 7.1), $100 \mathrm{mM} \mathrm{NaCl}, 1 \mathrm{mM}$ DTT, $1 \mathrm{mM}$ EDTA, $1 \mathrm{mM}$ EGTA, $10 \mathrm{mM} \beta$-glycerophosphate, $2 \mathrm{mM} \mathrm{Na}_{3} \mathrm{VO}_{4}, 25 \mathrm{nM}$ calyculin A, 1\% TX100, plus protease inhibitors (EDTA-free tablets; Roche). Protein concentration was determined by the Bradford reagent (BioRad). Immunoprecipitations were carried out with the indicated antibodies prebound to protein A/G-agarose (Santa Cruz), and washed in the lysis buffer containing 0.5 M $\mathrm{LiCl}$.

Experiments involving Ran used a different (Ran) lysis buffer: $50 \mathrm{mM}$ HEPES (pH 7.4), $0.1 \mathrm{M} \mathrm{NaCl}, 1 \mathrm{mM}$ DTT, $5 \mathrm{mM} \mathrm{MgCl}$, $2 \mathrm{mM} \mathrm{Na}_{3} \mathrm{VO}_{4}, 25 \mathrm{nM}$ calyculin A, $1 \%$ Triton X-100, plus protease inhibitors (EDTA-free tablets; Roche); IPs were washed with the same buffer. The binding of Ran to Nercc1 in vitro was carried out in Ran binding buffer (20 mM MOPS at pH 7.4, $0.1 \mathrm{M}$ potassium acetate, $5 \mathrm{mM}$ magnesium acetate, $2 \mathrm{mM}$ DTT, $0.5 \%$ BSA, $0.05 \%$ Tween-20); washes were carried out in the same buffer. Immunoblotting was carried out after separation of proteins by SDS-PAGE and transfer to PVDF membranes; blots were probed with the antibodies indicated, and bound antibodies were detected by ECL chemiluminescence (Amersham).

\section{Gel filtration}

The 293 cells were lysed in 1\% TX-100 lysis buffer, ultracentrifuged at $100,000 \mathrm{~g}$ for $40 \mathrm{~min}$, and loaded to a precalibrated HiPrep 16/60 Sephacryl S-300 High Resolution column (Pharmacia). Gel filtration was carried out in $50 \mathrm{mM}$ Tris $(\mathrm{pH} 7.5)$, $150 \mathrm{mM} \mathrm{NaCl}, 1 \mathrm{mM}$ DTT buffer at $0.5 \mathrm{~mL} / \mathrm{min}$.

\section{Protein kinase assays}

Protein kinase assays were carried out after immunoprecipitation; recombinant Nerccl was isolated using anti-Flag antibodies prebound to protein A/G-agarose beads. Endogenous Nercc1 was immunopurified using N1 antibodies prebound to protein A/G-agarose beads. Complexes were washed sequentially with lysis buffer and phosphorylation buffer (50 mM MOPS at $\mathrm{pH} 7.4$, $1 \mathrm{mM}$ DTT, 1 mM EGTA, $5 \mathrm{mM} \mathrm{MgCl}$, $10 \mathrm{mM} \beta$-glycerophosphate, $25 \mathrm{nM}$ calyculin A). Nercc1 autoactivation was carried out by incubation of immobilized Nerccl in phosphorylation buffer plus $100 \mu \mathrm{M} \mathrm{ATP}$ at $25^{\circ} \mathrm{C}$ for the indicated times. Activation was terminated by washing the immobilized Nerccl in phosphorylation buffer, and the protein activity achieved was assayed by incubation at $30^{\circ} \mathrm{C}$ in phosphorylation buffer supplemented with either $10 \mu \mathrm{M}$ or $100 \mu \mathrm{M}\left[\gamma^{-32} \mathrm{P}\right] \mathrm{ATP}$, with an exogenous substrate, usually histone $\mathrm{H} 3$, as indicated. Assays were stopped by addition of electrophoresis sample buffer and boiling, and the proteins were resolved by SDS-PAGE. ${ }^{32} \mathrm{P}$ incorporation was measured with a PhosphorImager system or by liquid scintillation counting, as indicated.

\section{Immunocytochemistry}

Cells grown on coverslips were rinsed with PBS, fixed in methanol at $-20^{\circ} \mathrm{C}$ for $15 \mathrm{~min}$, rinsed twice with PBS, and incubated 
for $30 \mathrm{~min}$ at room temperature with the appropriate dilution of primary antibody in PBS. To visualize endogenous Nercc1, affinity-purified anti-Nerccl peptide antibodies (N1 and $\mathrm{C} 1)$ were used at $10 \mu \mathrm{g} / \mathrm{mL}$. Microtubules were visualized with an $\alpha / \beta$-tubulin-specific antibody. Coverslips were washed with PBS, and incubated with labeled secondary antibodies from corresponding species in appropriate combination: fluorescein or rhodamine X-conjugated donkey anti-rabbit, Cy2 or rhodamine $\mathrm{X}$-conjugated donkey anti-mouse (each at 1:450). Incubation was terminated with a rinse in PBS, and the coverslips were mounted on a microscope slide. For immunodetection blocking, Nercc1 $\mathrm{Cl}$ or $\mathrm{N} 1$ antibody was incubated at $37^{\circ} \mathrm{C}$ for 30 min with a 15 -fold molar excess of immunizing peptide. After centrifugation at $12,000 \mathrm{~g}$ for $10 \mathrm{~min}$, the mixture was used for immunoblotting or immunocytochemistry, as indicated.

\section{Microinjections and time-lapse recordings}

For real-time observation of the effects of recombinant Nercc1 expression, both wild-type and variant, on cellular morphology and behavior during one cell cycle, HeLa cells grown on 25-mm glass coverslips were transfected with pEGFP-C2 vector or this vector encoding GFP fusions with Nercc1 wild-type, Nercc1 (K81M), or Nercc1(1-391) using Fugene (Roche Molecular Biochemicals). Fugene-containing medium was removed after $12 \mathrm{~h}$, and DMEM supplemented with $10 \%$ calf serum and penicillin-streptomycin was added after rinsing. The percentage of transfected cells undergoing division within $24 \mathrm{~h}$ was monitored. Using this transfection procedure, cells transfected with empty pEGFP-C2 underwent division at a frequency similar to nontransfected cells. The coverslips (in a Sykes-Moore chamber) were mounted on a microscope stage prewarmed to $37^{\circ} \mathrm{C}$; a region with the highest density of transfected cells (GFP-positive) was selected for observation, and phase contrast images were acquired using a $40 \times 1.0$ NA objective every $10 \mathrm{~min}$ for $25 \mathrm{~h}$. Light was kept to a minimum during image acquisitions and shuttered between acquisitions.

To observe the effect of anti-Nerccl antibodies on mitosis, PtK2 cells were grown to subconfluency on 25-mm round glass coverslips placed inside $35-\mathrm{mm}$ cell culture dishes. A cell in prophase was found using phase contrast optics and microinjected in the period between the nucleolar disassembly and nuclear envelope breakdown with either 2.5 or $10 \mu \mathrm{g} / \mu \mathrm{L}$ normal rabbit IgG (Jackson Immunoresearch) for control experiments, or with $2.5 \mathrm{mg} / \mathrm{mL}$ rabbit anti-Nerccl C- or N-terminus or kinase domain antibody with $0.5 \mu \mathrm{g} / \mu \mathrm{L}$ rhodamine-labeled dextran 3000 (Molecular Probes). Typically, the volume of microinjected material comprised $\sim 10 \%$ of cell volume. Immediately after microinjection, the coverslip with microinjected cells was placed in a Sykes-Moore chamber (Bellco Glass) filled with bicarbonate-free DMEM supplemented with $10 \%$ fetal Calf Serum. The chamber was transferred onto the stage of a Zeiss Axiovert $100 \mathrm{M}$ microscope maintained at $37^{\circ} \mathrm{C}$ with the aid of an Air-Therm heater controller (World Precision Instruments) and a custom-made microscope incubator. Microinjected cells were found by rhodamine fluorescence using a maximum possible density neutral density filter (typically, ND 1.0; Chroma Technology). Phase contrast images were acquired every 20 or $30 \mathrm{sec}$ with a Hamamatsu Orca-100 CCD camera driven by Metamorph 4.0 (Universal Imaging Corporation); we used a $100 \times 1.4$ NA objective and light was kept to a minimum during image acquisitions and shuttered between acquisitions.

\section{Acknowledgments}

We thank Y. Yin for Northern blots, Y. Lin for the mouse tissue protein membranes, E. Casacuberta for help with ORF prediction, and J. Prendable for help with the manuscript. We are grateful to A. Khodjakov and C. Rieder for help interpreting the anti-Nercc1 microinjection experiments. We are also grateful to I. Macara for the different Ran variant cDNAs and RCC1 cDNA, and to J. Maller for purified MPF. This work was supported in part by DK17776.

The publication costs of this article were defrayed in part by payment of page charges. This article must therefore be hereby marked "advertisement" in accordance with 18 USC section 1734 solely to indicate this fact.

\section{References}

Azuma, Y., Renault, L., Garcia-Ranea, J.A., Valencia, A., Nishimoto, T., and Wittinghofer, A. 1999. Model of the ran-RCC1 interaction using biochemical and docking experiments. $J$. Mol. Biol. 289: 1119-1130.

Belham, C., Comb, M.J., and Avruch, J. 2001. Identification of the NIMA family kinases NEK6/7 as regulators of the p70 ribosomal S6 kinase. Curr. Biol. 11: 1155-1167.

Bischoff, J.R. and Plowman, G.D. 1999. The Aurora/Ipllp kinase family: Regulators of chromosome segregation and cytokinesis. Trends Cell Biol. 9: 454-459.

Borodovsky, M. and McIninch, J. 1993. GeneMark: Parallel gene recognition for both DNA strands. Comput. Chem. 17: 123133.

Brunet, S. and Vernos, I. 2001. Chromosome motors on the move: From motion to spindle checkpoint activity. $E M B O$ Rep. 2: 669-673.

Burge, C. and Karlin, S. 1997. Prediction of complete gene structures in human genomic DNA. J. Mol. Biol. 268: 78-94.

Cimini, D., Howell, B., Maddox, P., Khodjakov, A., Degrassi, F., and Salmon, E.D. 2001. Merotelic kinetochore orientation is a major mechanism of aneuploidy in mitotic mammalian tissue cells. J. Cell Biol. 153: 517-527.

Dasso, M. 2001. Running on Ran: Nuclear transport and the mitotic spindle. Cell 104: 321-324.

Fry, A.M. and Nigg, E.A. 1995. Cell cycle. The NIMA kinase joins forces with Cdc2. Curr. Biol. 5: 1122-1125.

- 1997. Characterization of mammalian NIMA-related kinases. Methods Enzymol. 283: 270-282.

Glover, D.M., Hagan, I.M., and Tavares, A.A. 1998. Polo-like kinases: A team that plays throughout mitosis. Genes \& Dev. 12: 3777-3787.

Guo, Q., Xie, J., Dang, C.V., Liu, E.T., and Bishop, J.M. 1998. Identification of a large Myc-binding protein that contains RCC1-like repeats. Proc. Natl. Acad. Sci. 95: 91729177.

Heald, R. and Weis, K. 2000. Spindles get the ran around. Trends Cell Biol. 10: 1-4.

Hetzer, M., Bilbao-Cortes, D., Walther, T.C., Gruss, O.J., and Mattaj, I.W. 2000. GTP hydrolysis by Ran is required for nuclear envelope assembly. Mol. Cell 5: 1013-1024.

Holland, P.M., Milne, A., Garka, K., Johnson, R.S., Willis, C., Sims, J.E., Rauch, C.T., Bird, T.A., and Virca, G.D. 2002. Purification, cloning, and characterization of Nek8, a novel NIMA-related kinase, and its candidate substrate Bicd2. I. Biol. Chem. 277: 16229-16240.

Izzo, M., Antoccia, A., Degrassi, F., and Tanzarella, C. 1998. Immunofluorescence analysis of diazepam-induced mitotic apparatus anomalies and chromosome loss in Chinese hamster cells. Mutagenesis 13: 445-451. 
Roig et al.

Ji, Y., Walkowicz, M.J., Buiting, K., Johnson, D.K., Tarvin, R.E., Rinchik, E.M., Horsthemke, B., Stubbs, L., and Nicholls, R.D. 1999. The ancestral gene for transcribed, low-copy repeats in the Prader-Willi/Angelman region encodes a large protein implicated in protein trafficking, which is deficient in mice with neuromuscular and spermiogenic abnormalities. Hum. Mol. Genet. 8: 533-542.

Kahana, J.A. and Cleveland, D.W. 1999. Beyond nuclear transport. Ran-GTP as a determinant of spindle assembly. J. Cell Biol. 146: 1205-1210.

Kalab, P., Weis, K., and Heald, R. 2002. Visualization of a RanGTP gradient in interphase and mitotic Xenopus egg extracts. Science 295: 2452-2456.

Kandli, M., Feige, E., Chen, A., Kilfin, G., and Motro, B. 2000. Isolation and characterization of two evolutionarily conserved murine kinases (Nek6 and Nek7) related to the fungal mitotic regulator, NIMA. Genomics 68: 187-196.

Lies, C.M., Cheng, J., James, S.W., Morris, N.R., O'Connell, M.J., and Mirabito, P.M. 1998. BIMAAPC3, a component of the Aspergillus anaphase promoting complex/cyclosome, is required for a G2 checkpoint blocking entry into mitosis in the absence of NIMA function. J. Cell Sci. 111: 1453-1465.

Lu, K.P. and Hunter, T. 1995. Evidence for a NIMA-like mitotic pathway in vertebrate cells. Cell 81: 413-424.

Lu, K.P. and Means, A.R. 1994. Expression of the noncatalytic domain of the NIMA kinase causes a G2 arrest in Aspergillus nidulans. EMBO I. 13: 2103-2113.

Mayor, T., Meraldi, P., Stierhof, Y.D., Nigg, E.A., and Fry, A.M. 1999. Protein kinases in control of the centrosome cycle. FEBS Lett. 452: 92-95.

Moore, J.D. 2001. The Ran-GTPase and cell-cycle control. Bioessays 23: 77-85.

Mountain, V., Simerly, C., Howard, L., Ando, A., Schatten, G., and Compton, D.A. 1999. The kinesin-related protein, HSET, opposes the activity of Eg5 and cross-links microtubules in the mammalian mitotic spindle. J. Cell. Biol. 147: 351-365.

Nigg, E.A. 2001. Mitotic kinases as regulators of cell division and its checkpoints. Nat. Rev. 2: 21-32.

O'Connell, M.J., Osmani, A.H., Morris, N.R., and Osmani, S.A. 1992. An extra copy of nimEcyclinB elevates pre-MPF levels and partially suppresses mutation of nimTcdc25 in Aspergillus nidulans. EMBO J. 11: 2139-2149.

O'Connell, M.J., Norbury, C., and Nurse, P. 1994. Premature chromatin condensation upon accumulation of NIMA. EMBO J. 13: 4926-4937.

Osmani, S.A. and Ye, X.S. 1996. Cell cycle regulation in Aspergillus by two protein kinases. Biochem. J. 317: 633-641.

Osmani, S.A., Pu, R.T., and Morris, N.R. 1988a. Mitotic induction and maintenance by overexpression of a G2-specific gene that encodes a potential protein kinase. Cell 53: $237-$ 244.

Osmani, S.A., Engle, D.B., Doonan, J.H., and Morris, N.R. 1988b. Spindle formation and chromatin condensation in cells blocked at interphase by mutation of a negative cell cycle control gene. Cell 52: 241-251.

Osmani, A.H., McGuire, S.L., and Osmani, S.A. 1991a. Parallel activation of the NIMA and p34cdc2 cell cycle-regulated protein kinases is required to initiate mitosis in A. nidulans. Cell 67: 283-291.

Osmani, A.H., O'Donnell, K., Pu, R.T., and Osmani, S.A. 1991 b. Activation of the nimA protein kinase plays a unique role during mitosis that cannot be bypassed by absence of the bimE checkpoint. EMBO J. 10: 2669-2679.

$\mathrm{Pu}$, R.T. and Osmani, S.A. 1995. Mitotic destruction of the cell cycle regulated NIMA protein kinase of Aspergillus nidulans is required for mitotic exit. EMBO J. 14: 995-1003.

$\mathrm{Pu}, \mathrm{R} . T ., \mathrm{Xu}, \mathrm{G} ., \mathrm{Wu}$, L., Vierula, J., O'Donnell, K., Ye, X.S., and Osmani, S.A. 1995. Isolation of a functional homolog of the cell cycle-specific NIMA protein kinase of Aspergillus nidulans and functional analysis of conserved residues. J. Biol. Chem. 270: 18110-18116.

Renault, L., Nassar, N., Vetter, I., Becker, J., Klebe, C., Roth, M., and Wittinghofer, A. 1998. The 1.7 A crystal structure of the regulator of chromosome condensation (RCC1) reveals a seven-bladed propeller. Nature 392: 97-101.

Rieder, C.L., Schultz, A., Cole, R., and Sluder, G. 1994. Anaphase onset in vertebrate somatic cells is controlled by a checkpoint that monitors sister kinetochore attachment to the spindle. J. Cell Biol. 127: 1301-1310.

Rosa, J.L., Casaroli-Marano, R.P., Buckler, A.J., Vilaro, S., and Barbacid, M. 1996. p619, a giant protein related to the chromosome condensation regulator RCC1, stimulates guanine nucleotide exchange on ARF1 and Rab proteins. EMBO $J$. 15: 4262-4273.

Walczak, C.E. 2001. Ran hits the ground running. Nat. Cell Biol. 3: E69-E70.

Wu, L., Osmani, S.A., and Mirabito, P.M. 1998. A role for NIMA in the nuclear localization of cyclin B in Aspergillus nidulans. J. Cell Biol. 141: 1575-1587.

Ye, X.S., Xu, G., Pu, R.T., Fincher, R.R., McGuire, S.L., Osmani, A.H., and Osmani, S.A. 1995. The NIMA protein kinase is hyperphosphorylated and activated downstream of p34cdc2/ cyclin B: Coordination of two mitosis promoting kinases. EMBO J. 14: 986-994. 


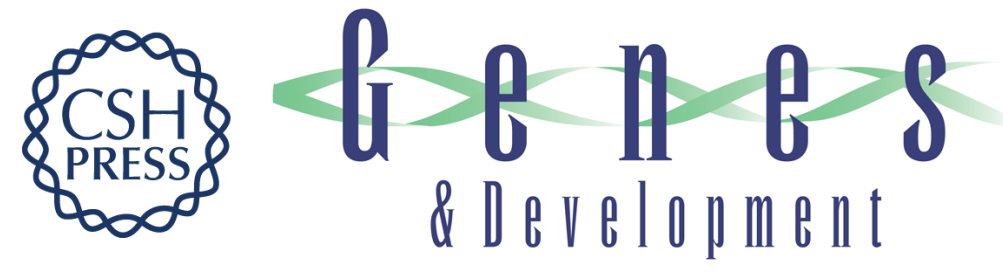

\section{Nercc1, a mammalian NIMA-family kinase, binds the Ran GTPase and regulates mitotic progression}

Joan Roig, Alexei Mikhailov, Christopher Belham, et al.

Genes Dev. 2002, 16:

Access the most recent version at doi:10.1101/gad.972202

Supplemental http://genesdev.cshlp.org/content/suppl/2002/07/04/16.13.1640.DC1
Material

References This article cites 39 articles, 11 of which can be accessed free at:

http://genesdev.cshlp.org/content/16/13/1640.full.html\#ref-list-1

License

Email Alerting Receive free email alerts when new articles cite this article - sign up in the box at the top

Service right corner of the article or click here.

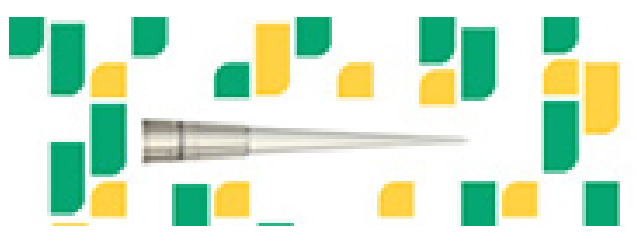

Focused on your science. 